WHAT SINGLE MIDLIFE WOMEN THINK ABOUT AND DO TO PROTECT

THEIR SEXUAL HEALTH

A Dissertation Presented to

the Faculty of the Graduate School

at the University of Missouri-Columbia

In Partial Fulfillment

of the Requirements for the Degree

Doctor of Philosophy

By

KIMBERLY C. HART

Dr. Maithe Enriquez, Dissertation Supervisor

May 2018 
(c) Copyright by Kimberly Hart

All Rights Reserved 
The undersigned, appointed by the dean of the Graduate School, have examine the dissertation entitled

\section{WHAT SINGLE MIDLIFE WOMEN THINK ABOUT AND DO TO PROTECT}

\section{THEIR SEXUAL HEALTH}

presented by Kimberly C. Hart, a candidate for the degree of doctor of philosophy and hereby certify that, in their opinion, it is worthy of acceptance.

Maithe Enriquez, PhD, RN, ANP-BC, FAAN

Tina Bloom, PhD, MPH, RN

An-Lin Cheng, PhD

Todd Ruppar, PhD, RN, GCNS-BC

Michelle Teti, DrPH 


\section{ACKNOWLEDGEMENTS}

The task of thanking all the individuals who have been a part of my PhD journey is a daunting task. To properly recognize all the co-workers, neighbors, friends, family and classmates who encouraged, supported, advised, listened along the way, gave me a shoulder to cry on and provided the distractions when I needed to clear my head, could easily take up more space than this dissertation its self. I Thank You!

To my advisor Dr. Enriquez, words fail to express how honored I am to have had you by my side. Your expertise, knowledge, positive attitude, grace, patience, sense of humor and "can do" attitude never failed to motivate and inspire me every step of the way. I am truly grateful.

Thank you to my committee members Dr. Tina Bloom, Dr. An-Lin Cheng, Dr. Todd Ruppar and Dr. Michelle Teti. I am grateful to each of you for your commitment of time and energy as you shared your individual expertise and experience with me as instructors and researchers.

To my Aunt Danell, you welcomed me into her home with open arms during many years of on-campus days and trips to Mizzou in between. Thank you for the home cooked meals, warm bed, dog care and late night chats. You are an amazing woman!

To my Parents Lee and Diane Hart, from the day I was born you encouraged and fostered my love of learning. You led by example with hard work and your own pursuits of lifelong learning. Thank you for your unconditional love and always being my biggest fans. 
To my husband Michael, for encouraging me, supporting me and never complaining about the evenings, weekends and holidays you spent alone during the last 7 plus years as I ran this academic marathon. You are my dream come true. I love you so much! 


\section{TABLE OF CONTENTS}

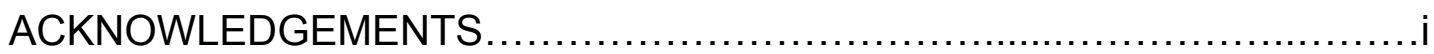

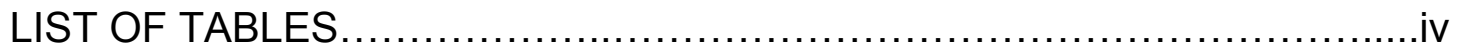

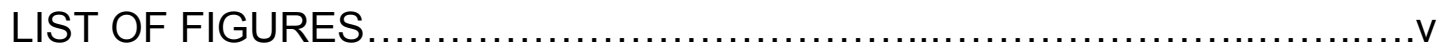

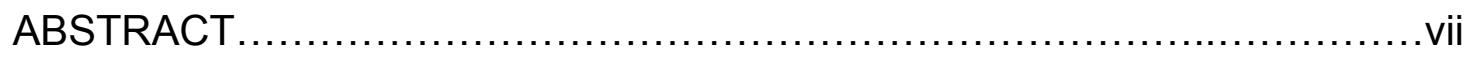

CHAPTER ONE INTRODUCTION......................................

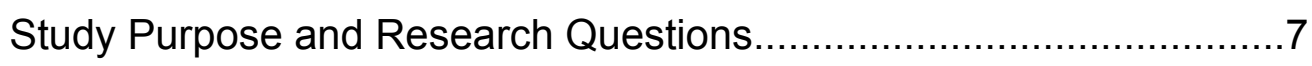

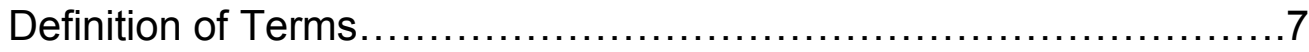

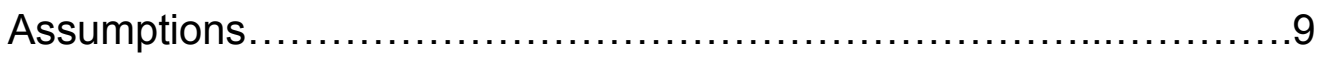

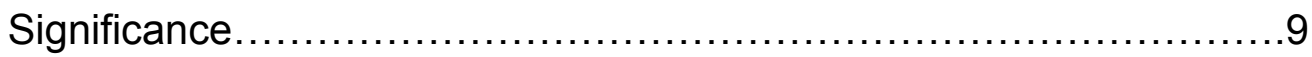

CHAPTER TWO REVIEW OF THE LITERATURE.......................11

Sexually Transmitted Infection Prevalence among Midlife Women......11

Sexually Transmitted Infection Risk Factors among Midlife women....13

Condom Use among Midlife Women..............................16

Interventions to Enhance Condom Use in Midlife Women..............21

CHAPTER THREE RESEARCH METHODOLOGY ...........................24

Research Design............................................. 24

Setting and Sample............................................24

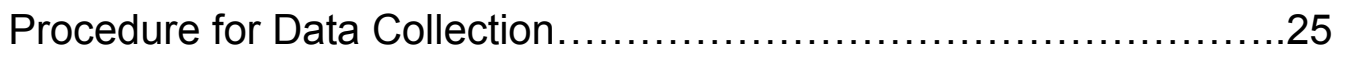

Protection of Human Subjects....................................... 27

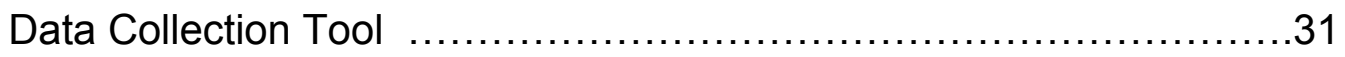

Data Analysis....................................................

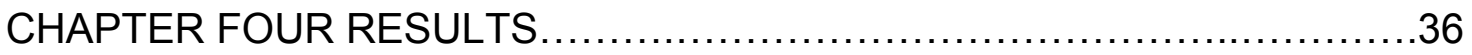


Reliability of the "STI and HIV risk prevention attitudes, and behaviors"

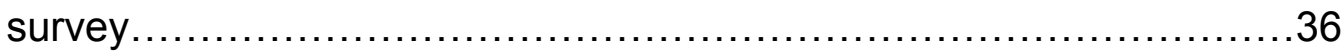

Participant Characteristics......................................... 37

Descriptions of the Variables of Interest..............................38

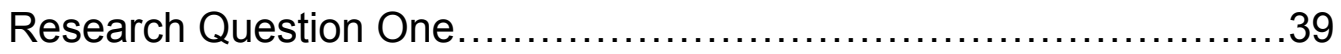

Research Question Two ............................................... 45

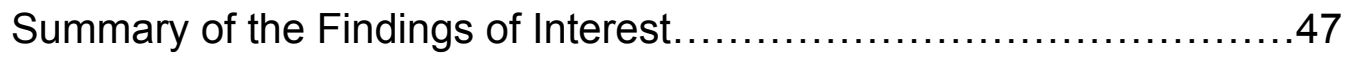

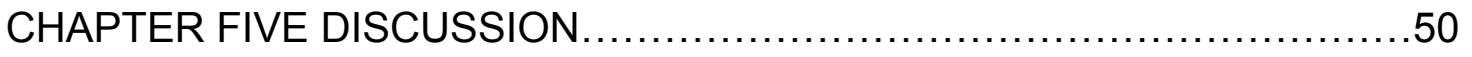

APPENDIX

A: HealthyWomen.org permission ....................................56

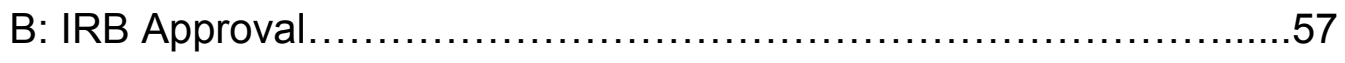

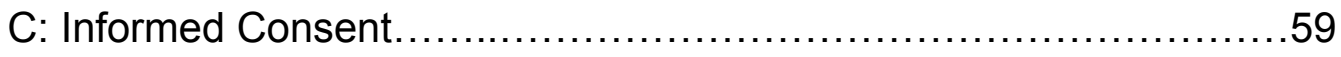

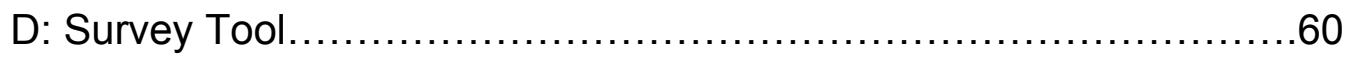

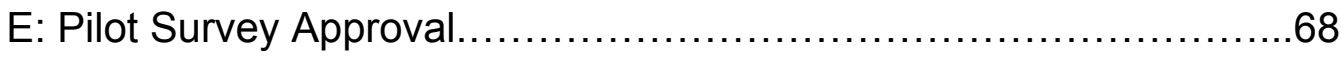

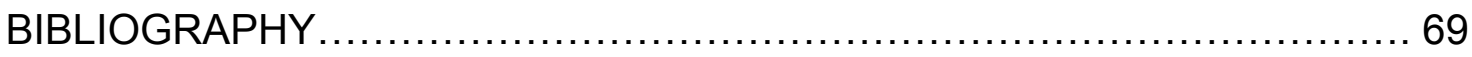

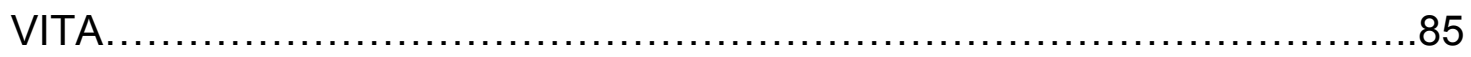




\section{LIST OF TABLES}

Table 3.1 Pilot Survey Findings, Insights, Revisions ...................30

Table 4.1 Spearman's rho Correlation Results Selected Demographics and theory of planned behavior...................................... 41

Table 4.2 Chi-square Analyses Selected Demographics and Condom Use........................................................................4

Table 4.3 Simultaneous Multiple Regression Analysis Summary for Attitude, Subjective Norms and Perceived Behavioral Control Predicting Intention to Use a Condom .......................................... 44

Table 4.4 Logistic Regression Predicting Condom Use with Last New Sexual Partner Among Single Midlife Women............................45

Table 4.5 Chi-Square Analysis of STI History, Number of New Sexual Partners and Condom Use. 


\section{LIST OF FIGURES}

Figure 1. Theory of Planned Behavior Diagram....................... 6 


\title{
WHAT SINGLE MIDLIFE WOMEN THINK ABOUT AND DO TO PROTECT
}

\section{THEIR SEXUAL HEALTH}

Kimberly Colette Hart, a candidate for the degree of doctor of philosophy

University of Missouri-Columbia, 2018

\begin{abstract}
Sexually transmitted infections (STI) are a significant public health problem among U.S. women. Single midlife women aged 40-59 are at particular risk for STI. Little is known about the factors that contribute to low sexual health protection and condom non-use in this population. The majority of research on STI prevention has focused on populations of younger women. This cross sectional study, guided by the theory of planned behavior examined relationships between STI perceived risk, attitudes, subjective norms, perceived behavioral control, condom use intention and sexual health behaviors. Data were collected with a convenience sample of single midlife women at risk for STI who participated via a web-based survey. Of the 611 women who entered the survey website, eligible participants $(n=285)$ were predominantly $40-49$ years of age (65.6\%), Caucasian (94.7\%), college graduates, $(62.1 \%)$ and employed (85.3\%). Approximately one-third $(31.6 \%, \mathrm{n}=90)$ indicated a previous STI diagnosis. Half $(49.5 \%)$ of the women reported they had used a condom use with the last new sexual partner. For the entire sample, attitudes, subjective norms, and perceived
\end{abstract}


behavioral control each significantly correlated with intention to use condoms with a new sexual partner. Logistic regression analysis showed that using a condom with a new sexual partner significantly increased as attitude $(p=.002)$ and intention $(p=.001)$ increased. Higher level of education correlated with decreased subject norms and intention towards condom use. There was a significant decrease in condom use of women with a college degree. A positive correlation was found between STI and number of new sexual partners. However, having more new sexual partners was significantly correlated with decreased condom use.

Findings indicated this sample of single midlife women had positive attitudes, subjective norms, perceived behavioral control and intention toward condom use. Yet, a condom was used only half of the time with new sexual partners. Findings from this study can inform interventions and programs that aim to enhance sexual health outcomes and reduce STI acquisition among midlife women. 


\section{CHAPTER ONE INTRODUCTION}

Sexually transmitted infections (STIs) pose a significant public health problem in the United States (National Institutes of Health (NIH), 2015). Annual surveillance estimates more than 20 million new cases of STIs each year among U.S. men and women (Centers for Disease Control and Prevention, 2017a), and a 2008 prevalence estimate, the most recent available, comes in at 110 million individuals annually (Satterwhite et al., 2013). STIs cost the U. S. health care system about $\$ 16$ million a year in direct medical costs for the treatment of the eight most common infections (Owusu-Edusei, Roby, Chesson, \& Gift, 2013). Productivity losses from missing work while seeking treatment for STIs pose an additional economic burden, often to those who are least able to afford it due to inequities arising from race/ethnicity, economics, or education (Harling,

Subramanian, Bärnighausen, \& Kawachi, 2014). The cost of lost wages and sick leave used for treating only nonviral STI are estimated to be higher than the cost of treatment. The Centers for Disease Control and the National Institutes of Health have highlighted the need to significantly reduce the number of STIs in order to diminish the negative health consequences and the economic burden associated with these preventable infections (CDC, 2017a; Harling et al., 2014; NIH, 2015; Owusu-Edusei et al., 2013).

\section{Negative Health Consequences of STIs}

The eight most common STIs are chlamydia, gonorrhea, hepatitis B virus (HBV), herpes simplex virus type 2 (HSV-2), human immunodeficiency virus (HIV), human papillomavirus (HPV), syphilis, and trichomoniasis (CDC, 2017). 
Early diagnosis renders chlamydia, gonorrhea, syphilis, and trichomoniasis readily treated and cured, though HBV, HSV-2, HIV and HPV are incurable. The Centers for Disease Control reports that HPV is the most prevalent STI in the U.S.; the majority of sexually active persons are exposed to it at some point. Sequelae of HPV can include cervical cancer and oropharyngeal or genital tract warts (CDC, 2017a). Accounting for approximately $25 \%$ of the prevalent STI infections in the U.S., HSV-2, HBV, and HIV are chronic infections with the potential for serious negative health outcomes. For instance, HSV-2 can result not only in painful chronic infection but during pregnancy, also in miscarriage or premature birth. It can be a potentially fatal if transmitted to the newborn, and chronic HBV can cause life threatening liver disease. In the U.S., HIV is responsible annually for 18,000 deaths (CDC, 2017b). Although individual states collect and report STI and HIV data, this review seeks to offer a broad understanding of the problem within the United States.

\section{STIs and Women}

Women account for 59 million cases $(51 \%)$ of STIs in the U.S. Although all sexually active persons are at risk for STIs, women are disproportionately affected by them. Women experience a larger economic and health toll from STIs through pelvic inflammatory disease, infertility and treatment to remove precancerous or cancerous cervical lesions from HPV infection (Sales \& Lang, 2011). STIs affect women differently than men as a result of their anatomy.

Vaginal tissue, a highly vascularized mucus membrane, is thinner and more delicate than the skin of a penis. The vagina's moist environment can promote bacterial growth, which increases the risk of acquiring an STI. Many women are 
asymptomatic with certain STIs, such as chlamydia and gonorrhea, or symptoms may go away while the infection persists. Women may confuse symptoms such as changes in vaginal discharge and irritation with a yeast infection, a miscalculation that can delay diagnosis and treatment. The presence of STIs can in some cases increase susceptibility to HIV (CDC, 2011; Peterman, Newman, Maddox, Schmitt, \& Shiver, 2015; Sales \& Lang, 2011).

\section{STI Prevention and Condom Effectiveness}

Effective STI prevention strategies exist, including abstaining from sex, reducing the number of sexual partners, and using condoms correctly and consistently (D'Anna et al., 2012; Steiner, Cates, \& Warner, 1999). Condom use has been studied extensively (Chimbiri, 2007; Weller \& Davis, 2002). Laboratory studies show that condoms protect against the smallest viral and bacterial pathogens (Carey, Lytle, \& Cyr, 1999; Eaton \& Hoesley, 2014; Lytle et al., 1997). Studies of infection rates between HIV discordant heterosexual couples who were condom nonusers versus consistent users revealed that using condoms consistently was extremely effective in preventing HIV transmission (Eaton \& Hoesley, 2014; Weller \& Davis, 2002). Moreover, consistent condom use has been shown to reduce the risk of acquiring additional STI's (Warner, Stone, Macaluso, Buehler, \& Austin, 2006). However, the degree of protection condoms provide is difficult to determine quantitatively due to STIs' various modes of transmission, such as skin to skin or genital fluids, and the variability of selfreporting of condom use and condom-protected intercourse (Crosby \& Bounse, 2012; Gallo et al., 2007). 


\section{STIs and Midlife Women}

Evidence suggests that STI infection is increasing among midlife women (Chesson, Zaidi, \& Aral, 2008; Fang, Oliver, Jayaraman, \& Wong, 2010). Centers for Disease Control data show that increasing numbers of women 40 and older are being diagnosed with STI and HIV infections (Blair, Paxton, \& Kamb, 2013). Several decades of U.S. and Canadian surveillance data found that STI rates among adults age 40-59 have increased by greater percentages or decreased at smaller rates than their younger counterparts (Chesson et al., 2008; Fang et al., 2010). For example, during 1997-2007, chlamydia and gonorrhea infections increased $86.8 \%$ in $15-29$ year olds compared to $165.9 \%$ in $40-59$ year olds (Fang et al., 2010). While surveillance and epidemiological data indicate that midlife women are experiencing significant rates of STIs, including HIV, the vast body of gender-based STI prevention research has focused primarily on adolescent and young adult women (Idso, 2009; Sherman, Harvey, \& Noell, 2005; Swartz, Harvey, Blanchard, Vawter, \& Gau, 2011). A thorough review of the literature found only a small number of studies dealing with the sexual health behaviors of midlife women (Bateson, Weisberg, McCaffery, \& Luscombe, 2012;

Jacobs \& Thomlison, 2009; Mallory, Harris, \& Stampley, 2009; Neundorfer,

Harris, Britton, \& Lynch, 2005; Prati, Mazzoni, \& Zani, 2015; Zablotsky \& Kennedy, 2003). None of the studies examined the attitudes, social norms, perceived behavioral control and intention to use condoms among single midlife women at risk for STIs. A need exists to better understand the sexual health 
practices and protective behaviors (i.e. condom use) of midlife women at risk for STI.

\section{Theory of Planned Behavior}

Many researchers have employed the theory of planned behavior (Ajzen, 1991) to predict and explain a variety of health related intentions and behaviors. The theory has been used in behavioral studies on topics such as physical activity (McGoey, Root, Bruner, \& Law, 2015), nutrition (Riebl et al., 2015), diabetes risk reduction (Akbar, Anderson, \& Gallegos, 2015), medication adherence (Kopelowicz et al., 2015), condom use for HIV/STI prevention, and HPV prevention (Albarracín, Fishbein, Johnson, \& Muellerleile, 2001; Bennett \& Bozionelos, 2000; Prati et al., 2015). The theory purports that the intention to perform a particular behavior (e.g. condom use) results from the combination of a person's 1) attitude about the benefits of that behavior, 2) beliefs of what society or significant others will think of them performing the behavior, and the degree of control they feel they have over factors influencing performance of the behavior. The strength of this intention is the measureable determinate of successful enactment of the actual behavior (Ajzen, 1991). A meta-analysis examining 67 studies evaluating heterosexual condom use determined that attitudes toward condoms were strongly associated with the intention to use condoms (Sheeran, Abraham, \& Orbell, 1999). 
Figure 1. Theory of Planned Behavior Diagram (Azjen, 2010)

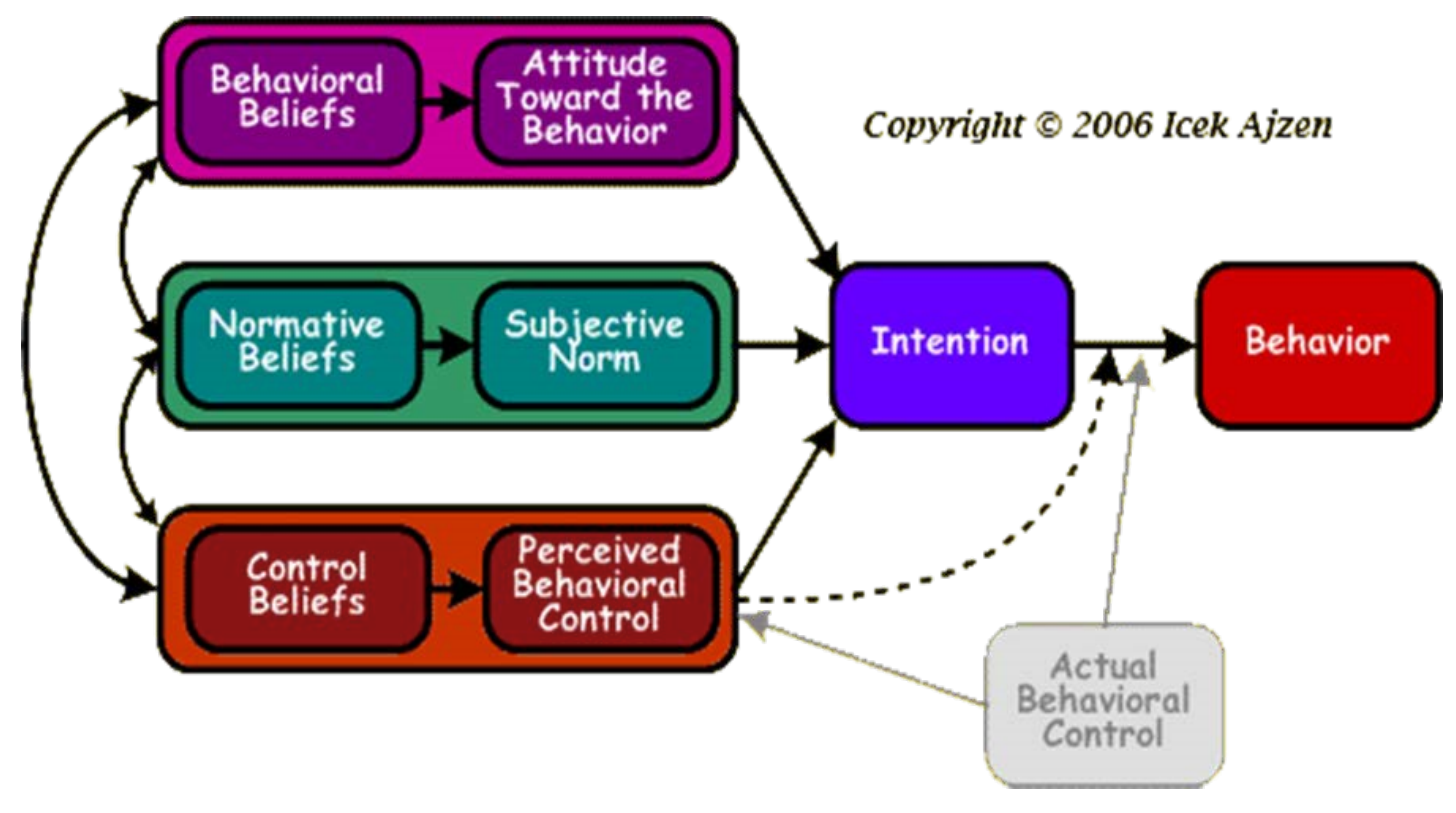

Published guidelines exist that aid investigators in using the theory of planned behavior to develop surveys addressing health research questions (Azjen, 2006). Other researchers have successfully used these guidelines to address research questions regarding sexual health (Ratanasiripong, 2015; Ratanasiripong, Cheng, \& Enriquez, 2013; Rich, Mullan, Sainsbury, \& Kuczmierczyk, 2014). These studies have dealt with college women and their risk of human papilloma virus risk, as well as adolescents and their STI risk (Ratanasiripong, 2015; Ratanasiripong et al., 2013; Rich et al., 2014).

This study of midlife women employed the theory of planned behavior to better understand the relationship of their condom use to their attitudes, social norms, perceived behavioral control and condom use intention. The results of this 
study can inform interventions for reducing STIs in the understudied population of midlife women at risk for STI.

\section{Study Purpose and Research Questions}

This cross-sectional study sought to examine the relationship between perceived risk for sexually transmitted infection, attitudes, subjective norms, perceived behavioral control, condom use intention and the sexual health protective behaviors of a convenience sample of single midlife women aged 4059 years across the United States. Participants were recruited primarily via social media through Facebook and Healthywomen.org.

This study addressed the following research questions:

$R Q$ 1: What is the relationship between demographic characteristics, attitudes toward condoms, subjective norms, perceived behavioral control, intention to use condoms, and uptake of condom use among single midlife women?

$R Q$ 2: Are there differences in condom use behavior between single midlife women who have had an STI and those who have not?

\section{Definition of Terms}

Sexually Transmitted Infection (STI): Sexually transmitted infections (STIs) are infections spread primarily through person-to-person sexual contact (World Health Organization [WHO], 2015).

Midlife: Midlife is about 40 to 60 years of age (Merriam-Webster, 2013). 
The John D. and Catherine T. MacArthur Foundation Research Network on Successful Midlife Development, http://midmac.med.harvard.edu/ defines midlife as the years between 30 and 70, with 40 to 60 at its core. Margie Lachman, author of the Handbook of Midlife Development writes that midlife begins somewhere around 40 and ends somewhere around 60 (Lachman, 2001). In this study, midlife was operationalized for the purpose of survey eligibility as women 40 to 59 years of age.

Attitude: The extent to which the individual has a positive or negative opinion of the behavior. Attitude toward the behavior (i.e., condom use) is based on whether the individual believes the behavior will result in a negative or positive outcome (Ajzen, 1991).

Subjective norm: The societal pressure an individual feels to perform a behavior. Subjective norms result from 1) an individual's beliefs regarding whether others who are important to him/her would either approve or disapprove of the behavior, and 2) the individual's incentive to conform (Ajzen, 1991).

Perceived behavioral control: The ease or difficulty an individual perceives in performing the behavior. Perceived behavioral control arises from one's experience, others' reported experiences and the individual's anticipated ease or difficulty of performing the behavior in the future (Ajzen, 1991).

Intention to perform behavior: The motivational drive that influences behavior. Intention is a collection of factors that indicate the amount of effort and planning an individual is willing to put forth to perform a behavior (Ajzen, 1991). Sexual behavior practices: Pertaining to sex-related activities (Farly, 2015). 
New sexual partner: A person with whom one has intercourse with for the first time and who may have other sexual partners.

Single: In this study, women were considered single if they were divorced, separated, widowed, or never married and not living with a significant other.

\section{Assumptions}

Based on The Theory of Planned Behavior, study assumptions are as follows:

1. Midlife women's condom use behavior results from their intention to perform the behavior. Intention is a collection of factors involving the amount of effort and planning an individual is willing to put forth to perform a behavior.

Intention to perform the behavior is the precursor to the behavior.

2. Midlife women's intentions to use condoms are influenced by their attitudes toward the behavior, subjective norms, and perceived behavioral control.

3. The greater the positive attitude, subjective norms and perceived behavioral control toward using condoms, the greater the midlife woman's intention will be to use them.

4. Demographic characteristics, experiences, and social norms influence condom use behavior through the resulting attitude toward condom use, subjective norms, and perceived behavioral control. 


\section{Significance}

Sexually transmitted infections among women remain a significant U.S. public health concern, not only due to the disproportionate number of infections but also to their economic and long-term consequences (CDC, 2017a).

Increasing the number of sexually active women accessing reproductive and sexual health services — including HIV and STI testing and treatment — not only can help reduce the disparities but also is a leading health indicator of the Healthy People initiatives (Healthly People 2020, 2011). However, STI rates among women 40 are increasing faster than those of younger adult women

(Chesson et al., 2008; Fang et al., 2010; Poynten, Grulich, \& Templeton, 2013). Rates of unprotected heterosexual intercourse with a casual partner increase as women age, putting midlife women at significant risk for STI, including HIV (Anderson, Warner, \& MacAluso, 2011). Despite these risks, this population has been underrepresented in gender-based sexual health research. It is critical for the field of healthcare and nursing to address the unique needs of this population of women with regard to sexual health protective behaviors (i.e. condom use behaviors) for STI prevention.

This dissertation study, guided by the theory of planned behavior (TPB), addressed a knowledge gap regarding the sexual health needs of midlife women who are in the perimenopause and menopause transition. This study examined the attitudes, social norms, and perceived behavioral control factors influencing the intention to use condoms among single, sexually active women. Study results have implications for both research and clinical practice. Findings will inform 
interventions to reduce the risk for STIs and increase practitioners' ability to provide midlife women tailored information about STI prevention. This study helps improve women's sexual health and increase condom as they transition through perimenopause and into menopause.

\section{CHAPTER TWO REVIEW OF THE LITERATURE}

The increased risk for sexually transmitted infections (STIs) that adolescents and young adults face is well documented (Haley, Puskar, Terhorst, Terry, \& Charron-Prochownik, 2013; Kogan et al., 2010; Ott, Katschke, Tu, \& Fortenberry, 2011). Studies of STI sequelae, such as infertility and ectopic pregnancy, and of STI prevention interventions, have focused primarily on women of childbearing age and youth aged 15-24 years (Idso, 2009; Kershaw, Magriples, Westdahl, Rising, \& Ickovics, 2009; Shepherd et al., 2010; Sherman et al., 2005). Few studies of STI risk factors, acquisition, prevention and intervention have included midlife women (i.e. age 40-59) (Idso, 2009; Minkin, 2010; Sherman, Harvey \& Noell, 2005). Recent research offers evidence that midlife women remain sexually active (Patel, Gillespie, \& Foxman, 2003), engage in risky sexual practices (Upchurch, Kusunoki, Simon, \& Doty, 2003), and experience and acquire STIs at an increasing rate (Poynten et al., 2013). In general, however, researchers have neglected this area. A need exists to better understand the unique risk factors and challenges that midlife women face and 
subsequently what factors increase their risk for exposure and acquisition of STIs, including HIV. Such findings could inform STI prevention interventions that enhance the sexual health of these women.

\section{STI Prevalence among Midlife Women}

Midlife women, defined as 40-59 years old (Lachman, 2001), have historically experienced STIs at a lower rate than younger women and have represented a smaller percentage of STIs (CDC, 2017a). However, this same surveillance data reveals an increase in STI infection rates over the years in this group (Drew \& Sherrard, 2008; Poynten et al., 2013). Midlife women's rates of STI infection are now increasing faster than those of younger women (Chesson et al., 2008; Fang et al., 2010; Xu,).

Heterosexual contact accounts for about $86 \%$ percent of the HIV infections in women (CDC, 2017c). Further, in 2016, 38.2\% of the approximately 6,541 new HIV diagnoses associated with heterosexual contact were among women age 40-59 (CDC,2017b). Between 1997 and 2007, rates of chlamydia increased $165.9 \%$, gonorrhea increased $133.3 \%$ and syphilis increased 11 fold, among adults 40-to 59-years-old, which is a rate of almost double, than those of 15-29 year olds ( $p<0.0001)$ (Fang et al., 2010). From 2009 to 2014, rates of chlamydia and gonorrhea have risen steadily for women 40 and older (CDC, 2018). A recent U.S. study found that trichomoniasis vaginalis was most prevalent in women age 41-60, with women 51-60 having the highest prevalence of trichomoniasis compared to those women who were 40 and younger (Munson et al., 2012). Washington state surveillance data from 1992-1998 identified primary herpes 
(HSV) infection outbreak as the most prevalent STI among women 40 and older (Xu et al., 2001). Many of the midlife women diagnosed with an STI in Xu's study did not seek treatment for urogenital symptoms but rather had a STI identified during a routine screening/clinic visit (Xu et al., 2001). While surveillance and epidemiological data indicate that midlife women are experiencing significant rates of STIs, including HIV, the vast body of genderbased STI prevention research has focused primarily on adolescent and young adult women (Idso, 2009; Sherman, Harvey, \& Noell, 2005; Swartz, Harvey, Blanchard, Vawter, \& Gau, 2011).

Undiagnosed STIs, such as HIV, are a public health issue because they increase the risk of the undiagnosed person unknowingly infecting others (CDC, 2017a). Untreated STIs also have serious sequelae. For example, chlamydia and gonorrhea can lead to the development of pelvic inflammatory disease and an increased risk of acquiring HIV infection (Sales, Milhausen, \& DiClemente, 2006). HIV is more likely to be diagnosed at a later stage in older women (Drew \& Sherrard, 2008). This delayed presentation for HIV treatment can result in more damage to the person's immune system and a shorter HIV to AIDS diagnosis interval (Drew \& Sherrard, 2008).

STI infection among midlife women is an important public health matter. Little published data are available regarding this group's sexual health behaviors and their needs when it comes to protecting their sexual health (Durvasula, 2014; Idso, 2009; Sherman et al., 2005). Only one STI-prevention intervention study 
was located in a thorough literature review focusing on the sexual health protection behaviors in mid-life women (Swartz et al., 2011).

\section{STI Risk Factors among Midlife Women}

The particular characteristics placing midlife women at increased risk for STIs are not fully understood. This is likely due to the fact that published STI and sexual health research has focused primarily on adolescents and younger adults, groups that traditionally have higher STI rates (Diclemente et al., 2008; Goesling, Colman, Trenholm, Terzian, \& Moore, 2014; Lazarus, SihvonenRiemenschneider, Laukamm-Josten, Wong, \& Liljestrand, 2010; Skinner, Parsons, Kang, Williams, \& Fairley, 2007). In addition, studies may have ignored midlife women because researchers assumed they are asexual, less sexually active, or monogamous and therefore at low risk (Beaulaurier, Fortuna, Lind, \& Emlet, 2014; Idso, 2009; Minkin, 2010; Sherman et al., 2005).

However, midlife women are indeed sexually active. In a survey describing the sexual health and behaviors of U.S. women $18-94$ years of age, $65 \%$ of those age $40-49$ and $46 \%$ of those $50-59$ years old reported sexual activity in the last 3 months (Patel et al., 2003). The latest American Association of Retired Persons (AARP) sexuality survey reports similar findings, with $58 \%$ of women age $45-49$ and $51 \%$ of women $50-59$ reporting sexual activity in the last 6 months (Fisher, 2010). The same survey (Fisher, 2010) found that being single and dating increased sexual activity, compared to married women.

Relationship transitions such as divorce, separation or widowhood provide opportunities for sexual activity with new sexual partners, which increases the 
risk for exposure to STIs. In 2010, $43 \%$ of women 18 years and older were age $40-64$, and $63 \%$ of this age group was divorced (U.S. Census Bureau, 2010). In a nationally representative random digit dialing survey of midlife and older women age $40-79$ who had divorced between the ages of 40 and $69,73 \%$ divorced in their 40 's, $22 \%$ in their 50 's and $6 \%$ in their 60 's. The majority of these women dated after divorce, with almost half reporting sexual activity (Montenegro, Aarp, \& Knowledge, 2004). Sexual activity after a relationship breaks up has been found to be associated with risky sexual behaviors such as multiple partners (Liddon, Leichliter, Habel, \& Aral, 2010; Marion \& Cox, 1996; Upchurch et al., 2003) and increased STI acquisition among women age 35-44, which was the oldest age group of women studied by Moreau, Beltzer, Bozon, \& Bajos (2011).

Physiological changes that occur during the perimenopause and menopausal transition result in lower estrogen levels. This can lead to thinning of the vaginal mucosa, and dryness of cervical and vaginal tissues. These changes increase women's susceptibility to micro abrasion cuts or tears during vaginal intercourse, boosting the chances of acquiring STIs (Lindau, Leitsch, Lundberg, \& Jerome, 2006; Poynten et al., 2013). Furthermore, midlife women may assume that STI symptoms relate to premenopausal or menopausal changes or other aging conditions; as a result, diagnosis is delayed and STI-associated morbidity increases (Idso, 2009; Minkin, 2010; Sherman et al., 2005).

Midlife women may not use condoms as contraception. Postmenopausal midlife women are no longer at risk for pregnancy and so do not need condoms' contraceptive characteristics (Baldwin \& Jensen, 2013). Other midlife women still 
can become pregnant but they use other contraceptive methods (Beaulaurier et al., 2014; Lindau et al., 2006; Sherman et al., 2005; Swartz et al., 2011). Both groups lose condoms' anti-STI properties.

Health-care providers' lack of awareness about midlife women's sexual activity, sexual behaviors and subsequent exposure to STIs may lead to less midlife women receiving less STI screening. In addition, providers' discomfort in discussing such topics has resulted in the lack of counseling for STI risks, prevention measures and STI testing of midlife women (Beaulaurier et al., 2014; Durvasula, 2014; Ferhing \& Mu , 2014; Grant \& Ragsdale, 2008; Minkin, 2010; Mugavero, Castellano, Edelman, \& Hicks, 2007). Providers' lack of communication with midlife patients about STI risk or attention to STI screening places midlife women at risk for a delayed HIV diagnosis, which significantly increases their risk of having AIDS at the time of HIV diagnosis (Mugavero et al., 2007; Sankar, Nevedal, Neufeld, Berry, \& Luborsky, 2011).

Disparities exist in HIV testing of midlife women, with only $10-15 \%$ of women age 45-64 having undergone such examinations (Durvasula, 2014). In a small survey of newly single women age $45-68$ and their primary care physicians, the majority of both groups thought it was the responsibility of the other to raise the topic of STI prevention (Grant \& Ragsdale, 2008). Although midlife women have been shown to possess moderately high general sexual health knowledge (Bateson et al., 2012; Ross, Humble, \& Blum, 2013), they score lower on STI/HIV knowledge.

Midlife women generally do not see themselves as being at risk for STIs, and they have been found not to use protective measures against STI or HIV, 
even when reporting high-risk behaviors (Prati et al., 2015; Upchurch et al., 2003; Zablotsky \& Kennedy, 2003). In order to fully protect sexual health, midlife women must have knowledge and awareness of personal susceptibility to infection and transmission. They must also be confident in their communication and negotiation skills for implementing prevention strategies with their sexual partners (Durvasula, 2014; Jacobs \& Thomlison, 2009; Prati et al., 2015; Upchurch et al., 2003; Zablotsky \& Kennedy, 2003).

\section{Condom Use among Midlife Women}

Consistent and correct condom use is the "gold standard" for STI prevention (Weller \& Davis, 2002). However, condom use peaks in younger age groups and declines with age (Anderson et al., 2011; Herbenick et al., 2010a; Reece et al., 2010). The literature repeatedly shows that increasing age is associated with decreasing condom use among women (Bateson et al., 2012; R. De Visser, 2007; Patel et al., 2003; Reece et al., 2010; Sanders et al., 2010). In U.S. national survey data from 1996-2008, condom use was highest among 1824 year olds at last intercourse with a causal partner (i.e. outside an ongoing relationship among all adults aged 18 years and older with one or more partners in past year) (Anderson et al., 2011; Herbenick et al., 2010b; Sanders et al., 2010). Condom use with casual partners declined as women aged, with less than $25 \%$ of women age $40-59$ reporting condom use at last sexual experience with such partners (Reece et al., 2010). This decline demonstrates that midlife women are at direct risk of acquiring an STI (Idso, 2009; Upchurch et al., 2003). 
In the United Kingdom, a web-based survey of sexual behavior found that a significantly larger percentage of post-menopausal women would not consider using condoms with a new partner since contraception was not required compared to premenopausal women (Cumming, Cochrane, Currie, Moncur, \& Lee, 2012). A nationally representative survey including U.S. women over 18 years of age reported condom use at last intercourse with a new or casual partner was lowest among women over 30 , compared to women younger than 30 years of age, independent of additional contraceptive method use (Sanders et al., 2010). In a telephone survey of Australian adults, De Vissor et.al, (2014) found that midlife women who had had heterosexual intercourse with a casual partner in the last 6 months reported inconsistent condom use. Women aged 4049 used condoms consistently only $32 \%$ of the time and women aged $50-59$ only $3.5 \%$ of time. When these same women were asked about condom use at last intercourse with a casual partner only $11 \%$ of women $40-49$ and $4.7 \%$ of women 50-59 reported using a condom (De Visser et al., 2014). This study confirms that single midlife women are putting themselves at risk for acquiring STIs as a result of not using condoms.

In a survey AARP conducted using women age 45 and older who were single, dating and sexually active every month for the last 6 months, respondents reported regular condom use only $32 \%$ of the time (Fisher, 2010). A crosssectional study found that single women over 34 years of age perceived condom use as a "turn off" because it suggested that one of the partners had a disease (Crosby, Milhausen, Yarber, Sanders, \& Graham, 2008). An Australian crosssectional study found that women older than $\mathbf{4 0}$ were more likely to discuss 
STIs before having sex with a new partner than younger women. However, the older women were less likely to refuse sex without a condom than their younger counterparts (Bateson et al., 2012). Although older women may be confident enough to discuss STIs with their partner, younger women appeared to be more experienced and comfortable insisting on condom use (Bateson et al., 2012). Understanding why a midlife woman would have sex without a condom even after discussing STIs would be valuable for developing interventions.

A study conducted in Los Angeles looking at the sexual behavior of unmarried women found condom use was lower among ever-married women (separated/divorced/widowed) between 40-49 and 50-64 who reported sexual activity in the last 12 months compared to never-married women in the same age groups. Further, ever-married midlife women with multiple sexual partners in the last 12 months reported less condom use than never-married midlife women. Ever-married and never-married women in the 40-49 and 50-64 age groups used condoms significantly less compared to their counterparts 18-29 years of age. Race was correlated with condom use. Regardless of age, African-American women used condoms to a significantly greater extent than white, Hispanic or Asian-American women. Education level was not found to be statistically significant indicator of condom use. The study dealt with no other socioeconomic factors (Upchurch et al., 2003).

Older women may find it more difficult than younger women to discuss condom use with a new partner. This may be due to ingrained societal meanings (Cook, 2012), such as raising the topic of condom use before having sex may 
imply a desire for sex. This is complicated by society's association of casual sex with promiscuity (Cook, 2012). Or, doing so may be thought to call into question the partner's character by implying that the partner may be a sexual health risk (Cook, 2012). Midlife women re-entering the dating scene after a relationship transition may have low self-esteem, which can make them vulnerable to forgoing safer sex practices in order to maintain new relationships (Rich, 2001). Women's need to find and maintain intimate relationships to build self-worth, coupled with societal messages regarding women and sexual behavior, can be detrimental to their sexual health.

Sterk and colleagues (2004) surveyed adult women to identify relationships between condom attitudes, factors influencing those attitudes, and risky sexual behavior. Respondents were 250 women, $24 \%$ of whom were 40 to 49 and $13.6 \%$ of whom were 50 and older. The study found that increased age was independently associated with negative condom attitudes and engaging in risky sexual behaviors, such as condom nonuse. The authors wrote that this may stem from the facts that older women primarily used condoms for birth control decades earlier, and that they have been largely excluded from HIVISTI education, prevention messaging and intervention efforts (Sterk, Klein, \& Elifson, 2004).

Jacobs and Thomlison (2009) surveyed 572 ethnically diverse women from south Florida to investigate how psychosocial factors such as self-silencing, selfesteem, sensation-seeking, HIV-related stigma and sexual assertiveness contribute to safer sex behaviors (condom use) in women age 50 and older. 
Higher self-silencing and HIV related stigma were independently related with lower safe sex behaviors. Also, age was a predictor of safer sex behaviors, with women 50-59 less likely than older women to engage in condom use (Jacobs \& Thomlison, 2009).

The studies presented in this section highlight that the intersection of relationship transition, new sexual partners, and decreased condom use increases midlife women's vulnerability to acquiring STIs (Idso, 2009; Marion \& Cox, 1996; Sherman et al., 2005). Little information is available on the sexual and protective practices of separated/divorced/widowed women, especially those over 40 years of age. Yet existing evidence supports the conclusion that condom use among single midlife women is alarmingly low (De Visser et al., 2014; Foster, Clark, Holstad, \& Burgess, 2012; Lindberg \& Singh, 2008; Patel et al., 2003; Schick et al., 2010; Upchurch et al., 2003).

\section{Interventions to Enhance Midlife Women's Condom Use}

A systematic review of literature by MacDonald, Lorimer, Knussen, and Flowers (2015) sought to identify evidence from interventions for increasing condom use among midlife and older adults. The review included studies of adults age 40 or older, regardless of gender, sexual orientation, race/ethnicity, nationality, socioeconomic, educational, marital status, HIV status or STI history. Studies that also included younger adults were considered if the intervention was tailored to the needs of the older population and data analyzed by age group. Studies were included if condom use intention or behavior was reported as an outcome measure. 
The review identified only four studies for analysis: three were conducted with HIV populations, with a majority of male participants (Coleman, Jemmott, Jemmott, Strumpf, \& Ratcliffe, 2009; Illa et al., 2008; Lovejoy \& Heckman, 2014). Only one study focused on heterosexual women over the age of 40 who had sex with a male partner in the last 3 months (Swartz et al., 2011). The study by Swartz et al. (2011) was the only research study located that examined an intervention to increase condom use, protect sexual and reproductive health and prevent STIs among midlife women.

The Swartz study was an internet-based, randomized controlled trial of 164 women age 40-55. The intervention group participated in a multimedia program featuring video, interactive tools, animations, and text. The content covered talking with your health care provider, talking with your partner, preventing pregnancy, reducing STI risk and information on anatomy, physiologic changes of aging in men and women, the menopause transition, fertility changes, and the menstrual cycle. The control group received text-based information developed for the study and that covered the same topics compiled from reproductive health content available on the internet from sites such as the CDC, WHO, FDA, NIH and Medline Plus.

Swartz found that baseline scores were similar across both groups for knowledge (anatomy and physiology, pregnancy prevention, STI prevention), attitudes and beliefs (importance of using contraceptive to prevent pregnancy, importance of using contraceptive to prevent STI, and importance of talking with partner and healthcare provider), self-efficacy (confidence in preventing 
pregnancy and talking with partner) and intentions (prevent an STI, talk with partner and use a contraceptive method). Participants were then surveyed at 7 and 30 days post intervention. The treatment group scored higher on intentions, and on attitudes and beliefs than did the control group at the 7-day time point. A final survey at 30 days found that the intervention group's intention scores remained higher. However, on the variable of condom use intention at every act of intercourse in the next 3 months, no differences were found between groups (Swartz et al., 2011).

In summary, there is evidence that midlife single women are sexually active with new sexual partners, yet they are not using condoms and so are experiencing increasing STI rates. Unfortunately, little information exists to explain why midlife women are less likely than their younger counterparts to protect their sexual health. This information is critical in order to develop ageappropriate interventions to help midlife women engage in healthful behaviors, such as condom use, that can significantly reduce their risk and incidence of STIs. Hence, this field needs research that can lead to a better understanding of the sexual and reproductive health perceptions and behaviors of midlife women. 


\section{CHAPTER THREE RESEARCH METHODOLOGY \\ Research Design}

This cross-sectional study utilized a convenience sample to examine relationships between demographic and sexual health characteristics, attitudes toward condoms, attitudes about STIs, subjective norms, perceived behavioral control, intention to use condoms, and uptake of condom use in single midlife women. The theory of planned behavior was the study's guiding theoretical framework.

\section{Setting and Sample}

Participants for this study consisted of single women: never married, divorced, separated or widowed. They ranged in age from 40 to 59 years. This range was chosen as it represents the midlife decades as well as the time frame in which most women enter perimenopause and complete the transition into menopause (Lachman, 2001). Inclusion criteria were: 1) women who selfidentified as heterosexual or bi-sexual, 2) able to read and write English, and 3) sexually active during the last 24 months with a new male partner. Participants were recruited using a multi-pronged approach via an online survey distributed through 1) postings by Healthywomen.org on the website's Facebook page (Appendix A), and 2) in the Nurse Practitioners in Women's Health E- News brief which is sent monthly to members and 3) a Facebook page about the study. Recruitment flyers, which contained a QR code linking participants to the survey, were disseminated to health care providers via word of mouth. The study's Facebook page contained a brief description of the study objective and intended sample population, and it invited eligible women to take the survey through the 
posted link. Targeted Facebook advertising promoted the research page to those fitting the study's age group, gender and relationship status requirements. Advertising was utilized for approximately 2 weeks to maximize participant response. Data were collected via an online survey using the Qualtrics $®$ platform.

The sample size calculation was based on the main analyses of regression. The power analyses were based on "the rule of thumb" of 20 subjects per predictor (Leech, Barrett and Morgan, 2008). Of the study's 10 predictors, the 5 main ones are attitudes, social norms, perceived behavioral control, intention to use condoms and condom use. The others were demographic variables (age, race/ethnicity, education, employment, and STI history). Based on 10 predictors and 20 subjects per predictor, a minimum of 200 subjects was needed.

\section{Procedures for Data Collection}

The University of Missouri-Columbia's Institutional Review Board approved this study (Appendix B). Posting of the website link to the online survey began in March 2017 and ended in June 2017. Each posting included a sentence inviting women to participate in a study about single women's health issues. Women were invited to click on the website link if were interested in participating in a short anonymous survey that would help provide information to nurse researchers about sexual health issues facing single midlife women. No gift or incentive was provided to participants.

Upon clicking the website link to the Qualtrics online survey, women viewed the study information page, which also dealt with informed consent (Appendix C). The page described the study's purpose and its objective of 
helping nurses to better understand the unique sexual health issues facing midlife single women. Eligibility criteria were stated: participants must be women between the ages of 40-59 who are single, separated, divorced or widowed and who have had sexual intercourse in the last 24 months with a new male partner.

At the end of the study information page, women could check a box stating that they agreed to participate in the study or a separate box stating that they did not wish to do so. If a woman checked "no," the page closed and she was thanked for participating. Participants who checked "yes" were taken into the first part of the survey, which contained the 3 eligibility questions regarding age, relationship status and sexual activity in the last 24 months. Participants who did not meet eligibility criteria were taken to a screen thanking them for their participation and exited from the survey. Participants who did meet eligibility continued to the survey. Participants who clicked on the survey link, completed and submitted the survey gave consent by their actions.

Data were collected via a one-time online survey. Qualtrics $®$ software was used to deliver the survey to participants. Qualtrics ${ }^{\circledR}$ is an online survey platform provided through the University of Missouri-Columbia. It is used by 1,600 colleges and universities in the United States to gather, view, and report data. Data were separated from the participant's email address and IP address before being transferred and stored in an SPSS database in a password protected account accessible only to primary investigator and her dissertation chair. 


\section{Protection of Human Subjects}

Permission was obtained to conduct this study from the University of Missouri - Columbia Institutional Review Board before beginning study activities. The IRB approval letter can be found in (Appendix B).

Steps taken to protect human subjects.

1. Participants entered their answers on a secure website.

2. Participant's name or other identifying information such as date of birth or address was not requested. The survey platform (Qualtrics) did not gather email or IP address with their answers, as the researcher's intent was to ensure anonymity.

3. Participants spent minimal time $\sim 15$ minutes completing the survey so as not to be onerous.

4. Participants engaged in this research study voluntarily.

5. Participants were informed that questions could be skipped if they wished not to answer.

6. Participants were informed that at any time should they wish to end their participation they were free to do so and survey was not submitted.

7. The contact information of the primary investigator, research chair and the University of Missouri-Columbia IRB office were on the consent page and at the end of the survey when the participant submitted or chose to quit the survey.

\section{Measures}

The survey, "STI and HIV risk prevention attitudes, and behaviors" 
(Appendix D), included the constructs found in the theory of planned behavior (Azjen, 1991) and followed the established questionnaire development guidelines for the theory of planned behavior (TPB) (Azjen, 2006). These guidelines are in the public domain (Azjen, 2006). The survey collected demographic data including STI history, condom use behaviors, attitude, subjective norms, perceived behavioral control, and intention to use condoms. Of the study's 10 predictors, the 5 main ones were attitudes, social norms, perceived behavioral control, intention and condom use. The others are demographic variables (Age, race/ethnicity, education, employment, and STI history). Outcome variables were intention to use condoms and condom use behavior.

The survey was based on previously published research using similar methods, and it included relevant topics (STI prevention and condom) based on a review of the literature (Azjen, 2006; Francis, 2004; Ratanasiripong, 2015; Ratanasiripong et al., 2013; Rich et al., 2014).

\section{Validity and Reliability Testing}

Content validity: The initial survey was reviewed for completeness by a panel of four women' health researchers, one of whom has experience in women's health research using the theory of planned behavior

Face validity: Three midlife women from the target population reviewed the survey for clarity, age appropriateness and readability of for the general population. Changes in wording and questionnaire length were made based on the recommendations of the reviewers and the dissertation committee. 


\section{Pilot Survey}

Upon the dissertation committee's approval, IRB approval and based on the survey development guidelines of the Theory of Planned Behaviors creator, a pilot survey was conducted. The survey was pilot tested with a convenience sample of 50 midlife women at a large healthcare provider conference in September of 2016 (see Appendix D). The pilot study used a paper-and-pencil survey format: No identifiers were collected. Participants $(n=50)$ volunteered to complete the survey and placed the completed survey in a designated box at the conference registration desk. The 41-question pilot survey covered demographics, 5 questions; Theory of Planned Behavior, 18; attitude toward condom use, 5; subjective norms, 5; perceived behavioral control, 4; and intention-to-use condoms, 4.

Initially, Cronbach's alpha using all 18 Theory of Planned Behavior items was 0.463 . After removing 4 items, Cronbach's alpha was 0.808 . The findings, insights gained, and plans for revision of the survey were provided to the dissertation committee and are presented in Table 3.1 
Table 3.1

Pilot Survey Findings, Insights, Revisions

\begin{tabular}{|c|c|c|}
\hline Finding & Insight & Revision for Final Study \\
\hline Missing data & $\begin{array}{l}\text { Although no identifiers were collected, } \\
\text { participants commented on the survey that } \\
\text { they were concerned about anonymity. } \\
\text { Use of a paper-and-pencil survey at an in- } \\
\text { person conference where the PI was a } \\
\text { participant likely contributed to this } \\
\text { concern. }\end{array}$ & $\begin{array}{l}\text { To decrease anonymity } \\
\text { concerns, the final study } \\
\text { used a web based } \\
\text { platform. Participants did } \\
\text { not provide any } \\
\text { identifying information, } \\
\text { enter their email or give } \\
\text { other contact information. }\end{array}$ \\
\hline Missing Data & $\begin{array}{l}\text { Use of the term "causal sex partner" } \\
\text { garnered many comments in the margins of } \\
\text { the survey, such as "I do not have casual } \\
\text { sex." }\end{array}$ & $\begin{array}{l}\text { The term "casual sex } \\
\text { partner" was changed to } \\
\text { "new sex partner." }\end{array}$ \\
\hline $\begin{array}{l}\text { Participants were } \\
\text { confused about } \\
\text { some of the } \\
\text { questions }\end{array}$ & $\begin{array}{l}\text { Relationship questions and attitude } \\
\text { questions were "lumped" together, which } \\
\text { likely resulted in confusion and missing } \\
\text { data. }\end{array}$ & $\begin{array}{l}\text { These questions were } \\
\text { separated to enhance } \\
\text { clarity. }\end{array}$ \\
\hline $\begin{array}{l}\text { Redundant } \\
\text { questions }\end{array}$ & Four questions were redundant. & $\begin{array}{l}\text { These questions were } \\
\text { deleted. }\end{array}$ \\
\hline $\begin{array}{l}\text { Question } \\
\text { clarity/readability }\end{array}$ & $\begin{array}{l}\text { Participants wrote suggestions for question } \\
\text { wording in the survey margins. }\end{array}$ & $\begin{array}{l}\text { These questions were } \\
\text { reworded. }\end{array}$ \\
\hline
\end{tabular}

Source: Pilot Survey

Based on the pilot study, minor changes were made to the survey questions. Most changes addressed formatting and rewording for clarity and readability. Four questions were deleted due to redundancy. No participant said the survey was too long. After the dissertation committee members reviewed the survey, it was revised and submitted for IRB approval. 


\section{Data Collection Tool}

This study's final survey consisted of 29 questions (see Appendix D). Demographic data were collected regarding age (40-49 or 50-59), race/ethnicity, educational level, employment status, and number of new sexual partners via categorical choice options. Participant's history of STI was collected via multiple choice. The theory of planned behavior questions related to attitude, subjective norms, perceived behavioral control, and intention to prevent STI acquisition were collected via a 7-point Likert Scale. Data were collected related to perceived risk for STIs and condom use behaviors via multiple choice. The survey concluded with an open-ended question allowing participants to give further information on their perceived STI risk of.

The survey's first three questions were on demographics to determine respondents' eligibility for the study. Question number four asked how the participant heard about the study. Questions five through nine asked for additional demographic information. Questions ten through 22 addressed attitude, subjective norms, perceived behavioral control, and intention to use condoms with a new sexual partner. The remaining questions covered sexual history and protective sexual behaviors over the last 24 months, along with the open-ended question giving participants a chance to offer further information related to their perceived risk of acquiring an STI. All theory of planned behavior variables were measured using a 7-point scale, based on the recommendations provided by Azjen (1981) and previous cross-sectional studies examining sexual health topics that have used this theory (Francis, 2004; Ratanasiripong, Cheng, \& Enriquez, 2013; Rich, Mullan, Sainsbury, \& Kuczmierczyk, 2014). Predictor 
variables of interest to this study were perceived risk of STI and/or HIV acquisition, attitudes toward condoms and condom use, subjective norms and perceived behavioral control pertaining to condom use. The outcome variables were intention to use condoms with new sexual partners and condom use behavior.

Attitude toward condom use was measured with three questions $(10,11$ and 12) with responses given on a 7-point Likert scale. Items included questions such as, "In my opinion, using a condom with a new sexual partner would be?" Participants provided a response ranging from ( $1=$ extremely bad to $7=$ extremely good); extremely good represents a positive response and extremely bad represents negative response. Lower numbers represent more negative attitudes, and higher numbers represent more positive attitudes. The higher the total score, the more positive the attitude regarding condom use.

Subjective norms were measured with three questions $(13,14,15$ and 16), which ask about condom use with responses given on a 7-point Likert-scale. Items included questions such as, "How much do you care about what the people who are important to you think you should do?" Participants provided a response ranging from ( $1=$ strongly disagree to $7=$ strongly agree). Strongly agree represents a positive response, and strongly disagree represents negative response. The higher the total score, the more positive subjective norms regarding condom use.

Perceived behavioral control was measured with three questions $(17,18$, and 19). Participants indicated their perceived control over using a condom at next intercourse with responses given on a 7-point Likert scale. Items included 
questions such as, "I feel confident that I will be able to use a condom with a new sexual partner?" Participants provided a response ranging from (1=strongly disagree to $7=$ =strongly disagree). Strongly agree represents a positive response, and strongly disagree represents negative response. The lower the total score, the more positive perceived behavioral control towards condom use. The responses for these three questions were reverse-coded in SPSS for data analysis.

Intention to use condoms was measured using four questions $(20,21,22$, and 23), which ask about condom use intention with responses given on a 7 point Likert-scale. Items included questions such as, "I plan to use a condom the next time I have sex with a new partner." Participants provided a response ranging from (1=strongly disagree to $7=$ strongly agree). Strongly agree represents a positive response while strongly disagree represents negative response. The higher the total score, the more positive the intention to use condoms.

Condom use behavior was measured with multiple-choice questions about number of new sexual partners during the last 24 months, condom use frequency with all new sexual partners and with last new sexual partner. If participants did not use a condom with last new sexual partner, they were asked about their perceived STI risk. Questions such as number of sexual partners in the past year, and condom use frequency were answered with fill-in-the-blank or multiplechoice options. Lastly, an open-ended follow-up question offered participants the opportunity to provide further information related to their previous risk assessment. 


\section{Data Analysis}

De-identified data were transferred from Qualtrics ${ }^{\circledR}$ into the Statistical Packet for the Social Sciences (SPSS) 23.0 database and analyzed. Descriptive statistics were used to describe the study sample and to summarize the demographic data (age, ethnicity, employment and educational attainment, STI history), sexual history and behaviors (number of new sexual partners in the past 24 months, condom use with new partners in last 24 month), and the theory of planned behavior variables (attitude, subjective norms, perceived behavioral control and intention to use condoms with a new sexual partner). The following statistical analyses were conducted to address the research questions:

Research Question 1: What is the relationship between demographic characteristics, attitudes toward condoms, subjective norms, perceived behavioral control, intention to use condoms, and condom use behavior among single midlife women?

1. Spearman's rho was used to describe the relationship between the independent/predictor variables (demographic and health characteristics attitudes, subjective norms, and perceived behavioral control) and dependent/outcome variables_-intention to use condoms and condom use behavior.

2. Chi-square and independent t-test was used to examine group differences on the independent/predictor variables (demographic and health characteristics) and dependent/outcome variable, condom use behavior. 
3. Multiple regression analyses were used to examine the relative contribution of the independent/predictor variables, attitude, subjective norms and perceived behavioral control on intention to use a condom among single midlife women.

4. Logistic regression analysis was used to examine the relative contribution of the independent/predictor variables attitude, subjective norms, perceived behavioral control and intention to the condom use behaviors among single midlife women.

Research Question 2: Are there differences in condom use behavior between single midlife women who have had an STI and those who have never had an STI?

1. Independent sample t tests were used to examine the mean differences on attitudes, subjective norms, perceived behavioral control, intention to use condoms and condom use behaviors between single midlife women who reported a history of STI and those without a history of STI.

2. Chi-square test was used to examine the differences in condom use behavior between women who reported an STI history and those without a history of STI. 


\section{CHAPTER FOUR RESULTS}

This study, which was guided by the theory of planned behavior, examined relationships between single midlife women's attitudes, social norms, perceived behavioral control and intention to use condoms. Six hundred and eleven (611) women provided consent and entered the online survey site, which began with three eligibility questions (age, relationship status, new sex partner in past 24 months) outlined in the methods section. There were women 326 who entered the online survey but did not meet the eligibility criteria. These women received a message that thanked them for their participation and were exited from the survey. A total of 285 women who entered the online survey met eligibility criteria and proceeded with the survey. These yielded 285 completed surveys eligible for analysis.

\section{Reliability of the "STI and HIV risk prevention attitudes, and behaviors" survey}

In order to determine the internal consistency reliability, Cronbach's coefficient alpha was calculated for Attitudes, Subjective Norms, Perceived Behavioral Control and Intention scale. The results were:

Attitudes toward condom use ( 3 items): Cronbach's coefficient alpha for the scale was 0.857 .

Subjective Norms toward condom use (4 items): Cronbach's coefficient alpha for the scale was 0.627 .

Perceived Behavioral Control toward condom use (3 items): Cronbach's coefficient alpha for the scale was 0.499 . 
Intention toward condom use (4 items): Cronbach's coefficient alpha for the scale was 0.906 .

\section{Participant Characteristics Demographics}

Of the women $(n=285)$ who completed the survey, most $(65.6 \%)$ were 4049 years of age, and the remainder (34.4\%) were $50-59$ years of age. The majority identified as Caucasian (94.7\%), were college graduates, $(62.1 \%)$ and employed (85.3\%). Almost one-quarter of respondents had never married $(24.2 \%)$, with the remainder of the sample $(75.8 \%)$ being either separated, divorced, or widowed.

\section{Sexual history}

All participants $(n=285)$ answered the question pertaining to history of STI. Approximately one-third $(31.6 \%, \mathrm{n}=90)$ of the respondents indicated they had been previously diagnosed with an STI. Of these, almost half reported having had a diagnosis of HPV (48.8\%). Other STIs reported were chlamydia (43.3\%) HSV (18.8\%) trichamoniasis (17.7\%) and gonorrhea (5.5\%). Percentages reflect the option to select more than one diagnosis of STI: $24.4 \%$ of participants reported two or more STI diagnoses. Participants were given the opportunity to write in the name of any unlisted STI diagnosis. Three women wrote in diagnoses: "crabs", "PID," and the third woman reported that she had never been told which STI she had been diagnosed with. Using the Chi-Square test, there were no significant relationships found between age groups (40-49 and 50-59) and history of STI diagnosis (yes/no) $(p=.062)$.

To be eligible for the study, women had to have reported sexual intercourse with at least one new male partner in the past 24 months. Women 
reported the number of new sexual partners in the last 24 months as follows: 1 new sexual partner (53.0\%); 2 new sexual partners (20.4\%), 3 new sexual partners $(10.5 \%)$ and 4 or more new partners (16.1\%). Using the Chi-square test, there were no significant relationships found between age groups (40-49 and $5059)$ and number of sexual partners in the past 24 months $(p=.778)$. However, using the independent $t$-test, a significant difference appeared between mean number of sexual partners in the past 24 months and report of STI diagnosis. Women reporting a history of STI had a higher number of new sexual partners than women who had fewer partners or who did not report a history of STI; (equal variances not assumed; $(t=-3.643, d f=153.68, p=.001)$. Condom use with last new sexual partner was reported by approximately half (49.5\%), as was no condom use with last new sexual partner.

\section{Descriptions of the Variables of Interest}

Attitude toward condom use. Among the women $(\mathrm{n}=285)$ who participated in this study the total overall mean score on attitude toward condom use was $6.32(S D=1.128)$ on a possible score range of 1-7. Using the independent $t$-test, no significant differences were found on scores for attitude toward condom use between women who reported a history of STI and women who did not (equal variances not assumed; $(t=-1.625, d f=229, p=.106)$.

Subjective norms. Among the women $(n=285)$ who participated in this study, the total overall mean score on subjective norms was $5.087(S D=1.273)$ on a possible score range of 1-7. Using the independent $t$-test, there were no significant differences in scores for subjective norms regarding condom use 
between women who reported a history of STI and women who did not $(t=-1.168$, $d f=166, p=.245)$.

Perceived Behavioral Control. Among the women $(n=285)$ who participated in this study, the total overall mean score on perceived behavioral control was $5.80(S D=1.160)$ on a possible score range of 1-7. Using the independent $t$-test, there were no significant differences in scores for perceived behavioral control regarding condom use between women who reported a history of STI and women who $(t=-.326, d f=175, p=.745)$.

Intention. Among the women $(\mathrm{n}=285)$ who participated in this study, the total overall mean score on intention to use a condom was $5.799(\mathrm{SD}=1.658)$ on a possible score range of $1-7$. Using the independent $t$-test, there were no significant differences in scores for intention regarding condom use between women who reported a history of STI and women who did not $(t=-.833, d f=.210$ $p=.406)$.

\section{Research Question One}

Research Question One: What is the relationship between demographic characteristics, attitudes toward condoms, subjective norms, perceived behavioral control, intention to use condoms, and uptake of condom use among single midlife women?

Relationship between the Theory of Planned Behavior and selected demographic characteristics

Spearman's rho was used to examine the relationship between selected demographic characteristics (i.e. age, education level, and STI history) and constructs of the Theory of Planned Behavior. Age was negatively correlated with 
subjective norms regarding condom use. Women age 50-59 had lower subjective norm scores toward condom use than women age 40-49 ( $p=.009)$. Age was negatively correlated with intention. Women age 50-59 had lower intention scores toward condom use than those age 40-49 ( $p=.018)$. A significant negative relationship appeared between education level and subjective norms. Women with a college degree had lower subjective norms toward condom use than those without a college degree $(p=.01)$. There was a significant negative relationship between education level and the intention to use a condom. Women with a college degree had lower intent to use a condom, compared to those without a college degree $(p=.008)$. There was a significant negative relationship between number of new sexual partners and subjective norms. Women with a higher number of new sexual partners had lower subjective norms toward condom use than women having fewer new partners $(p=.018)$. There was a significant negative relationship between number of new sexual partners and Intention. Women with a higher number of new sexual partners had lower intention toward condom use than women having fewer new partners $(p=.026)$. There was a significant positive relationship between number of new sexual partners and STI history. Women with a higher number of new sexual partners reported acquiring more STIs than women having fewer partners $(p=.000)$. No significant relationship was found between reported STI history and theory of planned behavior constructs (attitude, subjective norms, perceived behavioral control and intention). Among all participants, the predictor variables of attitude, subjective norms and perceived behavioral control were significantly correlated to a 
participant's intention to use a condom with a new sexual partner $(p=0.000)$. See Table 4.1

Table 4.1

Spearman's rho Correlation Results Selected Demographics and Theory of Planned Behavior $(\mathrm{N}=285)$

Variables

\begin{tabular}{|c|c|c|c|c|c|c|c|c|}
\hline & Age & Educ & STI Hx & Att & $\mathrm{SN}$ & PCB & Int & \#NSP \\
\hline Age & 1.0 & -.105 & -.110 & -.062 & $-.156 * *$ & -.067 & $-.141 *$ & -.054 \\
\hline Education & -.105 & 1.0 & .079 & -.044 & -.152 & -.021 & $-.158 * *$ & -.014 \\
\hline STI History & -.110 & .079 & 1.0 & .046 & -.074 & .017 & -.004 & $.219 * *$ \\
\hline $\begin{array}{l}\text { Number } \\
\text { New Sexual } \\
\text { Partners }\end{array}$ & -.054 & -.014 & $.219 * *$ & -.093 & $-.141 *$ & -.108 & $-.133^{*}$ & 1.0 \\
\hline Attitude & -.062 & -.044 & .046 & 1.0 & $.413 * *$ & $.436 * *$ & $.619 * *$ & -.093 \\
\hline Subjective Norm & $m .156 * *$ & $-.152^{*}$ & -.074 & $.413 * *$ & 1.0 & $.432 * *$ & $.550 * *$ & $-.141 *$ \\
\hline PBC & -.067 & -.021 & .017 & $.436 * *$ & $.432 * *$ & 1.0 & $.485^{* *}$ & -.108 \\
\hline Intention & -.141 & $-.158 *$ & -.004 & $.619 * *$ & $.550 * *$ & $.485^{* *}$ & 1.0 & $-.133 * *$ \\
\hline
\end{tabular}

Note: $E d u c=E d u c a t i o n, S T I H x=S T I$ History, Att=Attitude, $S N=$ Subjective norms, $P B C=P e r c e i v e d$ behavioral control, \#NSP=Number new sexual partners ** Correlation is significant at the 0.01 level (2-tailed)

${ }^{*}$ Correlation is significant at the 0.05 level (2-tailed) 


\section{Relationship between demographic characteristics and condom use}

\section{behaviors}

Spearman's rho was used to examine relationships between selected demographic characteristics (i.e. age, education level, employment, and STI history), number of new sexual partners and condom use behaviors. No significant relationship was found between the two age groups (40-49 and 50-59) and condom use. A significant negative relationship was found between education level and condom use. Women with a college degree were less likely to use condoms with a new sexual partner than were women without a college degree $(p=.049)$. There was a significant negative relationship between number of new sexual partners and condom use. Women reporting a higher number of new sexual partners were less likely to use condoms with a new sexual partner than women having fewer new partners $(p=.001)$. No significant relationship was found between women reporting an STI history versus those not reporting an STI history and condom use with new sexual partners $(p=.066)$.

Chi-square was used to examine the difference between selected demographic characteristics (i.e. age, education level and STI history), number of new sexual partners and condom use behaviors. No difference was found between the two age groups (40-49 and 50-59) and condom use. A significant difference appeared between education level and condom use. Women with a college degree were less likely to use condoms with a new sexual partner than were women without a college degree $(p=.049)$. A significant difference was found between number of new sexual partners and condom use. Women with higher numbers of new sexual partners were less likely to use condoms than 
women with fewer new sexual partners $(p=.010)$. No difference was found between women who reported a history of STI and those who did not when it came to condom use with new sexual partners. See Table 4.2

Table 4.2

Chi-square analyses selected demographics and condom use

\begin{tabular}{lrr}
\hline & $\begin{array}{c}\text { Entire } \\
\text { Group }\end{array}$ & p-value \\
\hline Age & $(\mathrm{n}=285)$ & 0.684 \\
$40-49$ & $65.6 \%$ & \\
$50-59$ & $34.4 \%$ & \\
& & $.049 *$ \\
Education Level & $(\mathrm{n}=285)$ & \\
No College Degree & $37.8 \%$ & \\
College Degree & $62.1 \%$ & \\
& & \\
& & \\
& & \\
STI History & & \\
Yes & $(\mathrm{n}=285)$ & \\
No & $31.6 \%$ & .066 \\
Number New Sexual Partners & $(\mathrm{n}=\mathbf{2 8 5})$ & \\
1 & $52.9 \%$ & \\
2 & $20.3 \%$ & \\
3 & $11.2 \%$ & \\
$>3$ & $17.1 \%$ & \\
& & \\
\hline
\end{tabular}

* Correlation is significant at the 0.05 level (2-tailed

Contribution of Theory of Planned Behavior predictor variables of attitude, subjective norms and perceived behavioral control on intention to use a condom and condom use with a new sexual partner

Multiple regression examined the relative contribution of the theory of planned behavior predictor variables (attitude, subjective norms and perceived behavioral control) to predict the intention to use a condom with a new sexual 
partner. This combination of attitude, subjective norms and perceived behavioral control significantly predicted intention to use a condom, $F(3,277)=120.68$, $(p<.001)$, with all three variables significantly contributing to the prediction. The adjusted $\mathrm{R}$ squared value was .56 , which indicates that the model explained $56 \%$ of the variance in intention. See Table 4.3

Table 4.3

Simultaneous Multiple Regression Analysis Summary for attitude, subjective norms and perceived behavioral control predicting intention to use a condom $(\mathrm{N}=285)$

\begin{tabular}{lcccc}
\hline Variables & B & SEB & $\boldsymbol{\beta}$ & $\boldsymbol{p}$-value \\
\hline Attitudes & .616 & .064 & .425 & $.001^{\text {** }}$ \\
Subjective Norms & .464 & .057 & .356 & $.001^{\text {** }}$ \\
Perceived Behavioral Control & .279 & .062 & .196 & $.001^{* *}$ \\
Constant Intention & -2.085 & .433 & & \\
\hline
\end{tabular}

Note. $R^{2}=.56 ; F(3,277)=120.68, p<.001$

** Correlation is significant at the 0.001 level (2-tailed).

From the results presented above, attitude, subjective norms and perceived behavioral control contributed significantly to all study participants' intention to use a condom ( $p=.001)$. Thus, logistic regression was conducted to assess the relative contribution of the predictor variables (attitudes, subjective norms, perceived behavioral control and intention) for condom use. (The assumptions of observation being an independent variable being linearly related to the logit were checked and met.)

The Omnibus Test of Model Coefficients indicated that, when all four variables were considered together, the logistic regression model was statistically significant $(\mathrm{X} 2=87.96, \mathrm{df}=4, \mathrm{n}=285, p<0.001)$. According to the model summary, 26.9\% (Cox and Snell $R^{2}$ ) and $35.8 \%\left(\right.$ Nagelkerke $\left.R^{2}\right)$ of the variance in whether 
participants used a condom with a new sexual partner can be accounted for by the four variables. Table 4.4 presents the odds ratios, which suggest that the odds of using a condom with a new sexual partner increase as attitude $(p=002)$ and intention $(p=.001)$ increase. Women who used a condom with their last new sexual partner had a more positive attitude and greater intention scores than those who did not. See Table 4.4

\section{TABLE 4.4}

Logistic Regression Predicting condom use with last new sexual partner among single midlife women $(\mathrm{N}=285)$

\begin{tabular}{lcccc}
\hline Variables & B & SE & Odds Ratio & $p$-value \\
\hline Attitude & .668 & .224 & 1.950 & $.002^{*}$ \\
$\begin{array}{l}\text { Subjective Norms } \\
\quad\end{array}$ & .144 & .133 & 1.155 & .279 \\
$\begin{array}{l}\text { Perceived Behavior } \\
\text { Control }\end{array}$ & .050 & .142 & 1.051 & .726 \\
Intention & & & & \\
\end{tabular}

** Correlation is significant at the 0.001 level (2-tailed).

* Correlation is significant at the 0.01 level (2-tailed).

\section{Research Question Two}

Research Question 2: Are there differences in condom use behavior between single midlife women who have had an STI and those who have never had an STI?

\section{Differences between Theory of Planned Behavior and STI History}

Independent sample t tests were used to examine differences in the mean scores of attitudes, subjective norms, perceived behavioral control and intention toward condom use between women who report a history of STI and women who do not. No differences were observed on attitudes toward condom use between 
women who reported a history of STI and women who did not $(p=.147)$. No differences were observed on subjective norms toward condom use between women who reported a history of STI and women who do not $(p=.238)$. No differences were observed on perceived behavioral control toward condom use between women who reported a history of STI and women who do not $(p=.746)$. No differences were observed on intention toward condom use between women who reported a history of STI and women who did not $(p=.440)$.

\section{Differences between STI history and condom use}

Chi-square was used to examine the differences in condom use with new sexual partners between women who reported a history of STI and those who did not. No difference was found between condom use with new sexual partners among women who reported a history of STI versus women who did not $(p=.376)$. Perceived risk of STI acquisition without the use of a condom was split approximately into thirds, with $35.4 \%$ reporting high risk, $35.4 \%$ reporting medium risk and $29.2 \%$ reporting low risk.

\section{Differences between STI history and number of new sexual partners}

Chi-square was used to assess the differences in STI history and number of new sexual partners. A significant difference was found between the number of new sexual partners and STI history. Women who reported a history of STI had more new sexual partners compared to women who did not report a history of STI ( $p=.001)$. See Table 4.5 
Table 4.5

Chi-Square Analysis of STI History, Number of new sexual partners and Condom use $(\mathrm{N}=285)$

\begin{tabular}{|c|c|c|c|c|c|}
\hline \multirow[t]{2}{*}{ Variables } & & \multicolumn{2}{|c|}{ STI History } & \multirow[b]{2}{*}{ Total } & \multirow[t]{2}{*}{$p$-value } \\
\hline & & Yes & No & & \\
\hline \multirow{3}{*}{$\begin{array}{l}\text { Used a condom with last new } \\
\text { sexual partner }\end{array}$} & Yes & 42 & 102 & 144 & .376 \\
\hline & No & 48 & 93 & 141 & \\
\hline & Total & 90 & 195 & 285 & \\
\hline \multirow[t]{5}{*}{$\begin{array}{l}\text { Number of New sexual partners } \\
\text { Past } 24 \text { months }\end{array}$} & 1 & 35 & 116 & 151 & $.001 *$ \\
\hline & 2 & 17 & 41 & 58 & \\
\hline & 3 & 17 & 12 & 30 & \\
\hline & $<3$ & 21 & 25 & 46 & \\
\hline & Total & 90 & 195 & 285 & \\
\hline
\end{tabular}

${ }^{* *}$. Correlation is significant at the 0.001 level (2-tailed).

\section{A Summary of the Findings of Interest}

This study generated significant findings, of which the following are key:

1. Age was negatively correlated with subjective norms and intention towards condom use. Women age 50-59 had lower scores for subjective norms and intention toward condom use than women age 40-49. However, there was no correlation between age and reported condom use with new sexual partners.

2. For the entire sample $(n=285)$, education level was negatively correlated with subjective norms and intention to use condoms. Women with a college degree had lower scores for subjective norms and intention than women without a college degree. 
3. For the entire sample, education level was negatively correlated with condom use. Women with a college degree reported less condom use with new sexual partners than women without a college degree.

4. For the entire sample, attitudes, subjective norms, and perceived behavioral control each significantly correlated with intention to use condoms with a new sexual partner.

5. For the entire sample, attitude and intention were both significantly related to condom use with a new sexual partner, while subjective norms and perceived behavioral control were not.

6. Between women who reported a history of $S T I(n=90)$ and those who did not $(n=195)$, there was no significant correlation observed between condom use with new sexual partners.

7. Between women who reported a history of STI and those who did not, no differences were found on the attitudes, subjective norms, perceived behavioral control and intention to use condoms.

8. Number of new sexual partners was significantly correlated with history of STI. Women who reported a history of STI had more new sexual partners than women who did not.

9. For the entire sample, number of new sexual partners was negatively correlated with condom use. As the number of new sexual partners increased, condom use with new sexual partners decreased.

10. Between women who reported a history of STI and those who did not, condom use with new sexual partners did not differ. 
11. One-half of the participants used a condom with last new sexual partner (49.5\%), yet more than two-thirds self-reported as high/medium risk $(70.8 \%)$ for STI. 


\section{CHAPTER FIVE DISCUSSION}

This study was conducted to examine single midlife women's perceptions and behaviors with regard protecting sexual health. The study sample $(n=285)$ was homogeneous: predominately Caucasian (95\%) single women who were employed (85\%). Hence, this study did not examine how ethnicity or employment status affected sexual health perceptions and behaviors.

Findings indicated that this sample of single midlife women had positive attitudes, subjective norms, perceived behavioral control and intention toward condom use. No differences were observed between women who reported a history of STI and those who did not. Overall, women in this study had a positive attitude toward using a condom with a new sexual partner. Participants reported using a condom with a new sexual partner as 'good, valuable and beneficial'. Overall, women had positive subjective norms and believed that people who were important to them would want them to use a condom with a new sexual partner. Participants believed that women like themselves used condoms with new sexual partners. Further, women also believed their healthcare provider would advise and support their use of condoms with a new sexual partner. Overall, study participants reported high perceived behavioral control and confidence that using a condom with a new sexual partner was their choice. According to the Theory of Planned Behavior, as attitudes, subjective norms and perceived behavioral control increase, the probability of intention to use condoms with a new sexual partner increases as does the probability of using a condom with a new sexual partner. This study's results confirmed that attitudes, subjective norms and perceived behavioral control are positively correlated with 
intention. Participants reported the expectation and plan to use a condom with a new sexual partner. Attitudes, subjective norms, perceived behavioral control and intention were significantly positively correlated to condom use with a new sexual partner. However, logistic regression analysis revealed that attitudes and intention predicted condom use. The significant relationship between attitudes, intention and condom use are consistent with previous research (Gabriele Prati, Mazzoni, \& Zani, 2014)

This study identified several significant associations between selected demographic variables and the theory of planned behavior. Age was negatively correlated with subjective norms and intention toward condom use. Women age 50-59 had lower scores for subjective norms and intention towards condom use than women who age 40-49. A prior study also found perceived behavioral control and intentions decreased with age (Prati et al., 2014). These findings of decreased subjective norms and intention to use condoms with a new sexual partner among women age 50-59 could result from the narrow age range of the study sample. Interestingly, the findings of decreased subjective norms and intention to use condoms did not result in any significant differences in reported condom use between age groups. Further research with larger samples of midlife women are needed to understand age considerations that could affect midlife women's subjective norms and intentions regarding condoms. It is possible that the age differences could stem from the younger women's risk for pregnancy. Moreover, social and professional interactions with friends and healthcare providers may differ between age groups and so affect subjective norms and consequently intention to use condoms. 
Looking closer at age, a few prior studies reported a decrease in condom use between single women age 40-49 and those 50-59 years of age (Sanders et al., 2010; Upchurch, Kusunoki, Simon, \& Doty, 2003). However, many of these same studies do not differentiate between age groups or specific age-group data but instead report differences in a categorical fashion (e.g. above or below 30 , younger vs. older) (Anderson, Warner, \& MacAluso, 2011; Reece et al., 2010; Sterk, Klein, \& Elifson, 2004). Therefore, examining differences in condom use between age groups of women $40-49$ and 50-59 who are already predisposed to less condom use may require larger sample sizes than the current study.

Education level was negatively correlated with subjective norms and intention to use condoms. Women with a college degree had lower scores for subjective norms and intention than women without a college degree. No other published studies have reported this association between among midlife women. The current study also found that education level was associated with differences in condom use. Women with a college degree reported less condom use with new sexual partners than women without a college degree. Prior studies including women age 40-59 conducted in various settings (e.g. state/population based telephone survey and community based in person interviews) found that education level was not associated with differences in condom use (Sanders et al., 2010; Sterk et al., 2004; Upchurch et al., 2003).

No differences were found in the attitudes, subjective norms, perceived behavioral control and intention to use condoms between women who reported a history of STI and those who did not. No prior studies were found that examined the association between history of STI and midlife women's attitudes, subjective 
norms, perceived behavioral control and intention to use condoms. Prior research conducted in adolescents and young adults on this topic has shown mixed results (Crosby et al., 2004; Reid et al., 2013).

This cross-sectional study found that women who used a condom with their last new sexual partner had a more positive attitude and greater intention scores that those who did not use a condom with their last new sexual partner. This is consistent with previous studies of women 40 years of age, which found that older women were more likely to have negative attitudes toward condoms (Bateson, Weisberg, McCaffery, \& Luscombe, 2012), and less likely to report condom use with a new partner (Sterk et al., 2004). Caution should be utilized when interpreting the associations between number of new partners and condom use as the studies were conducted in different settings using different samples. Although this cross-sectional study did not find a difference in condom use between midlife women who reported a history of STI and those who did not, a prior study reported differences in HIV-related knowledge, attitudes, and behavior among adult psychiatric outpatients with and without a history of STI (Vanable, 2007). Participants with an STI history expressed stronger intentions to use condoms and perceived themselves to be at greater risk for HIV. Yet, those with an STI history were also more likely to report sex with multiple partners and more frequent unprotected sex in the past 3 months (Vanable, Carey, Carey, \& Maisto, 2007). A study of condom use after STI diagnosis found that overall use was higher in younger adults compared to older adults (Wallace, 2015). Of note was the finding that a distant STI was associated with less condom use among older adults compared to younger adults (Wallace, Blood, Crosby, \& Shrier, 2015). 
The lack of available evidence about condom use differences in midlife women with and without an STI history underscores the need for further research with this group. For example, future studies could examine relationships between time since STI diagnosis or type of STI and condom use.

This study found significant associations between number of new sexual partners in the past 24 months, history of STI and condom use. Increased number of partners was significantly associated with decreased condom use. Prior studies including age 40-59 also found associations between increasing numbers of sexual partners and less condom use (Prati, Mazzoni, \& Zani, 2015; Sterk et al., 2004; Upchurch et al., 2003). Caution should be utilized when interpreting the associations between number of new partners and condom use as the studies were conducted in different settings using different samples.

Further, the current cross-sectional study found that the number of new sexual partners was significantly correlated with history of STI. Women who reported a history of STI reported a higher number of new sexual partners in the past 24 months than women who did not report a history of STI. Due to this study's cross-sectional nature, causal association between number of new sexual partner and history of STI cannot be made (Polit \& Beck, 2007).

This cross-sectional study found no significant difference in condom use between women who reported a history of STI and those who did not. Furthermore, as the number of new sexual partners in the past 24 months increased, there was a significant decrease in condom use. These findings are cause for concern, given that increased numbers of sexual partners increase STI risk, especially when coupled with lack of condom use (CDC, 2016). This study 
had inherent limitations that must be considered when interpreting the results.

The study employed a convenience sample of self selected midlife women recruited using a variety of web-based and social media sites; hence generalizability of findings is limited. All data were self-reported, which is subject to bias. However, the study's use of the theory of planned behavior may have reduced such bias, as it has been shown to do elsewhere (Armitage \& Conner, 1999; Zemore \& Ajzen, 2014). Recruitment was primarily through social media, which resulted in a predominantly white sample. Participants' homogeneity precluded the ability to conduct analyses by race or ethnicity, thereby limiting the generalizability of the results. Finally, for future studies, revision of the perceived behavioral control survey items should be considered, given the Cronbach's alpha for the subscale of 0.46 .

Despite its limitations, this study's findings add to knowledge about the attitudes, intentions and behaviors of single midlife women with regard to protecting their sexual health. Few sexual health studies in the literature have focused on this group. Findings from this study suggest that single midlife women have positive attitudes about condom use with a new sexual partner. Although attitude, subjective norm and perceived behavioral control variables did predict the intention to use condoms, it was attitude and the intention that predicted condom use. When it comes to intention to use condoms, this study suggests attention should be given to differences in education level and subjective norms. Finally, the identification of discrepancies between risk perception and condom use among midlife women provides opportunity for future intervention research. 


\section{Appendix A \\ Healthy Women.org Letter of Support}

From: Elizabeth Battaglino <ebattaglino@healthywomen.org>

Sent: Thursday, March 9, 2017 4:05 PM

To: Hart, Kimberly C. (MU-Student); Vera Sizensky

Subject: Re: Hello and Survey

On Mar 9, 2017, at 1:59 PM, Elizabeth Battaglino <ebattaglino@healthywomen.org>

wrote:

Kimberly, hello wow it's been a while :)

So here is what we can do - we are able to promote on our social channel with a link to your survey. Hope that works for you!

If so, we can implement quickly.

Beth

Beth Battaglino, RN

Chief Executive Officer

HealthyWomen.org

Email: ebattaglino@healthywomen.org Mobile:

732-241-5030|@bbcrn

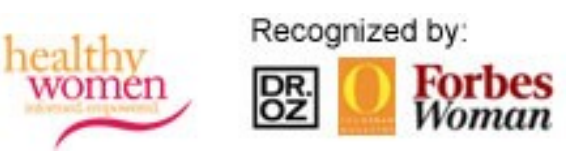




\section{APPENDIX B}

\section{IRB Approval}

\section{Institutional Review Board}

University of Missouri-Columbia

190 Galena Hall; Dc074.00

Columbia, MO 65212

573-882-3181irb@missouri.edu

September 21, 2016

Principal Investigator: Kimberly Hart

Department: Nursing-PHD

Your Exempt Application to project entitled ATTITUDES, SOCIAL NORMS, PERCEIVED BEHAVIORAL CONTROL AND CONDOM USE INTENTION IN SINGLE MIDLIFE WOMEN AGE 40-59 years was reviewed and approved by the MU Institutional Review Board according to the terms and conditions described below:

IRB Project Number 2005080 IRB Review

Number $\quad 213528$

Initial Application Approval Date September 21, 2016

IRB Expiration Date $\quad$ September 21, 2017

Level of Review Exempt

Project Status Active - Open to Enrollment

Exempt Categories $\quad 45$ CFR 46.101b(2)

Risk Level Minimal Risk

External Funding In-kind (donation of equipment or services)

The principal investigator (PI) is responsible for all aspects and conduct of this study. The PI must comply with the following conditions of the approval:

1. No subjects may be involved in any study procedure prior to the IRB approval date or after the expiration date. 
2. All unanticipated problems, adverse events, and deviations must be reported to the IRB within 5 days.

3. All changes must be IRB approved prior to implementation unless they are intended to reduce immediate risk.

4. All recruitment materials and methods must be approved by the IRB prior to being used.

5. The Annual Exempt Form must be submitted to the IRB for review and approval at least 30 days prior to the project expiration date. If the study is complete, the Completion/Withdrawal Form may be submitted in lieu of the Annual Exempt Form

6. Maintain all research records for a period of seven years from the project completion date.

7. Utilize all approved research documents located within the attached files section of eCompliance. These documents are highlighted green.

If you are offering subject payments and would like more information about research

participant payments, please click here to view the MU Business Policy and

Procedure: http://bppm.missouri.edu/chapter2/2_250.html

If you have any questions, please contact the IRB at 573-882-3181 or irb@missouri.edu.

Thank you,

MU Institutional Review Board 


\section{Appendix C}

\section{Informed Consent}

IRB \#2005080 C

\section{ATTITUDES, SOCIAL NORMS, PERCEIVED BEHAVIORAL CONTROL AND CONDOM USE INTENTION IN SINGLE MIDLIFE WOMEN AGE 40-59 years}

Welcome to the Midlife Sexual Protective Behaviors Study Page

My name is Kimberly Hart, I am a women's health nurse practitioner working on my PhD in nursing at the University of Missouri-Columbia.

I am studying what single women age 40-59 have experienced, think, believe, and plan to do when it comes to protecting themselves from sexually transmitted infection when/if they have sexual intercourse with a new sexual partner.

Your participation in this research will provide important information on how single women protect themselves. Information on the topic of sexual health among women age 40-59 is very limited. Your responses will provide information to researchers who will use it help women like you, protect themselves in the future.

You are invited to participate in a research project about sexual health history, and behaviors related to condom use. This online survey should take about 10 minutes to complete.

Participation is voluntary, and responses will be kept anonymous, to the degree permitted by the technology being used.

You have the option to not respond to any questions that you choose. You can also choose to stop your participation at any time while you are answering questions and your responses will not be submitted. Submission of the survey will be interpreted as your informed understanding and consent to participate.

Your answers will only be reported as group results. No identifying information from you, the individual will be submitted with the survey responses.

If you have any questions about the research or would like a copy of the results, please contact the Principal Investigator, Kimberly Hart, via email at kcht2c@mail.missouri.edu or the faculty advisor, Dr. Maithe Enriquez at enriquezm@missouri.edu If you have any questions regarding your rights as a research subject, contact the UM Institutional Review Board (IRB) at (573) 8829585 or email at irb@missouri.edu

Please print or save a copy of this page for your records and thank you so much for your participation!*

By clicking on the YES (I Agree), completing and submitting it, I (participant) understand and agree to participate in this research survey.

YES, (I Agree) No 


\section{Appendix}

\section{Survey Tool}

Q1 Welcome to the Midlife Sexual Protective Behaviors Study. My name is Kimberly Hart, I am a women's health nurse practitioner working on my $\mathrm{PhD}$ in nursing at the University of Missouri-Columbia. I am studying what single women age 40-59 have experienced, think, believe, and plan to do when it comes to protecting themselves from sexually transmitted infection when/if they have sexual intercourse with a new sexual partner. Your participation in this research will provide important information on how single women protect themselves. Information on the topic of sexual health among women age 40-59 is very limited. Your responses will provide information to researchers who will use it help women like you, protect themselves in the future. You are invited to participate in a research project about sexual health history, and behaviors related to condom use. This online survey should take about 10 minutes to complete. Participation is voluntary, and responses will be kept anonymous, to the degree permitted by the technology being used. You have the option to not respond to any questions that you choose. You can also choose to stop your participation at any time while you are answering questions and your responses will not be submitted. Submission of the survey will be interpreted as your informed understanding and consent to participate. Your answers will only be reported as group results. No identifying information from you, the individual will be submitted with the survey responses. If you have any questions about the research or would like a copy of the results, please contact the Principal Investigator, Kimberly Hart, via email at kcht2c@mail.missouri.edu or the faculty advisor, Dr. Maithe Enriquez at enriquezm@missouri.edu If you have any questions regarding your rights as a research 
subject, contact the UM Institutional Review Board (IRB) at (573) 882-9585 or email at irb@missouri.edu Please print or save a copy of this page for your records and thank you so much for your participation! *By clicking on the YES (I Agree), completing and submitting it, I (participant) understand and agree to participate in this research survey.

lick to write the question text

YES (I Agree) (1)

O NO (2)

Condition: YES (I Agree) Is Selected. Skip To: What is Your Age? Condition: NO Is Selected. Skip To: End of Survey.

Q2 What is Your Age?

O 40-49 (1)

O 50-59 (2) O Other (3)

Condition: Other Is Selected. Skip To: End of Survey.

Q3 In the last 24 months, have you had sexual intercourse with a new male partner?

$\bigcirc$ Yes (1) $\bigcirc$ No (2)

Condition: No Is Selected. Skip To: End of Survey.

Q4 What is your relationship status?

Single/Never Married (1)

Widowed/Divorced/Seperated (2) $\bigcirc$ Married (3)

Condition: Married Is Selected. Skip To: End of Survey.

Q5 How did you hear about this study?

O Healthywoman.org website (1)

Flyer (2)

Word of mouth (3)

Q6 What is your race/ethnicity?

Caucasian/White (1) 
O Black/African American (2)

O Asian (3)

Native American/Pacific Islander (4)

O Hispanic/Latino (5)

O Other (6)

Q7 What is your education level?

Did not finish high school (1)

High school graduate (2)

Some college (3)

O college graduate (4)

Q8 What is your employment status?

Full time (1)

O Part time (2)

Not working (3)

Q9 Have you ever been diagnosed with a sexually transmitted infection (STI)? (Check all that apply)

$\square$ Gonorrhea (1)

Chlamydia (2)

$\square$ Syphilis (3)

$\square$ Genital Herpes (4)

- Human Papilloma Virus (HPV) or Genital Warts (5)

$\square$ Trichamoniasis (6)

$\square$ Other (7)

$\square$ No, I have never been diagnosed with an STI (8)

Q10 Please take a moment during the next 3 questions to tell us what you think about using condoms with a new sexual partner. Please choose the answer that best describes your thoughts/feelings. Please note that some of the questions and answers might seem similar but they are not the same. In my opinion, using a condom with a new sexual partner would be:

\begin{tabular}{|l|l|l|l|l|l|l|}
$\begin{array}{l}\text { Extremely } \\
\text { Worthless } \\
(1)\end{array}$ & $(2)$ & $(3)$ & $(4)$ & $(5)$ & $(6)$ & $\begin{array}{l}\text { Extremely } \\
\text { Valuable } \\
(7)\end{array}$ \\
\hline
\end{tabular}




\begin{tabular}{|l|l|l|l|l|l|l|l|}
\hline $\begin{array}{l}\text { Please } \\
\text { select } \\
\text { One (1) }\end{array}$ & 0 & 0 & 0 & 0 & 0 & 0 & 0 \\
\hline
\end{tabular}

Q11 In my opinion, using a condom with a new sexual partner would be:

\begin{tabular}{|c|c|c|c|c|c|c|c|}
\hline & $\begin{array}{l}\text { Extremely } \\
\text { Bad (1) } \\
\text { (1) }\end{array}$ & (2) & (3) & (4) & (5) & (6) & $\begin{array}{l}\text { Extremely } \\
\text { Good } \\
\text { (7) }\end{array}$ \\
\hline $\begin{array}{l}\text { Please } \\
\text { select one } \\
\text { (1) }\end{array}$ & 0 & 0 & 0 & 0 & 0 & 0 & 0 \\
\hline
\end{tabular}

Q12 In my opinion, using a condom with a new sexual partner would be:

\begin{tabular}{|l|l|l|l|l|l|l|l|} 
& $\begin{array}{l}\text { Extremely } \\
\text { Harmful } \\
(1)\end{array}$ & $(2)$ & $(3)$ & $(4)$ & $(5)$ & $(6)$ & $\begin{array}{l}\text { Extremely } \\
\text { Beneficial } \\
(7)\end{array}$ \\
\hline $\begin{array}{l}\text { Please } \\
\text { Select } \\
\text { one (1) }\end{array}$ & 0 & 0 & 0 & 0 & 0 & 0 & 0 \\
\hline
\end{tabular}

Q13 Please indicate the importance or whether you agree or disagree as indicated with the statements below. How much do you care about what the people who are important to you think you should do:

\begin{tabular}{|l|l|l|l|l|l|l|l|} 
& $\begin{array}{l}\text { Strongly } \\
\text { Agree } \\
(1)\end{array}$ & $(2)$ & $(3)$ & $(4)$ & $(5)$ & $(6)$ & $\begin{array}{l}\text { Strongly } \\
\text { Disagree(7) }\end{array}$ \\
\hline $\begin{array}{l}\text { Please } \\
\text { select one } \\
(1)\end{array}$ & 0 & 0 & 0 & 0 & 0 & 0 & 0 \\
\hline
\end{tabular}

Q14 I would use a condom with a new sexual partner if my health care provided advised me to do so:

\begin{tabular}{|l|l|l|l|l|l|l|}
$\begin{array}{l}\text { Strongly } \\
\text { Agree } \\
(1)\end{array}$ & $(2)$ & $(3)$ & $(4)$ & $(5)$ & $(6)$ & $\begin{array}{l}\text { Strongly } \\
\text { Disagree(7) }\end{array}$ \\
\hline
\end{tabular}




\begin{tabular}{|l|l|l|l|l|l|l|l|}
\hline $\begin{array}{l}\text { Please } \\
\text { select one } \\
(1)\end{array}$ & 0 & 0 & 0 & 0 & 0 & 0 & 0 \\
\hline
\end{tabular}

Q15 Most women like me will use a condom with a new sexual partner:

\begin{tabular}{|l|l|l|l|l|l|l|l|}
\hline & $\begin{array}{l}\text { Strongly } \\
\text { agree (1) }\end{array}$ & $(2)$ & $(3)$ & $(4)$ & $(5)$ & $(6)$ & $\begin{array}{l}\text { Strongly } \\
\text { disagree } \\
(7)\end{array}$ \\
\hline $\begin{array}{l}\text { Please } \\
\text { select } \\
\text { one (1) }\end{array}$ & 0 & 0 & 0 & 0 & 0 & 0 & 0 \\
\hline
\end{tabular}

Q16 It is expected I will use a condom with a new sexual partner:

\begin{tabular}{|l|l|l|l|l|l|l|l|} 
& $\begin{array}{l}\text { Strongly } \\
\text { Agree (1) }\end{array}$ & $(2)$ & $(3)$ & $(4)$ & $(5)$ & $(6)$ & $\begin{array}{l}\text { Strongly } \\
\text { Disagree } \\
(7)\end{array}$ \\
\hline $\begin{array}{l}\text { Please } \\
\text { select } \\
\text { one (1) }\end{array}$ & 0 & 0 & 0 & 0 & 0 & 0 & 0 \\
\hline
\end{tabular}

Q17 Please indicate whether you agree or disagree or the amount of difficulty as indicated with the statements below.

Whether or not I use a condom with a new sexual partner is primarily up to me:

\begin{tabular}{|l|l|l|l|l|l|l|l|} 
& $\begin{array}{l}\text { Strongly } \\
\text { Agree (1) }\end{array}$ & $(2)$ & $(3)$ & $(4)$ & $(5)$ & $(6)$ & $\begin{array}{l}\text { Strongly } \\
\text { Disagree } \\
(7)\end{array}$ \\
\hline $\begin{array}{l}\text { Please } \\
\text { select } \\
\text { one (1) }\end{array}$ & 0 & 0 & 0 & 0 & 0 & 0 & 0 \\
\hline
\end{tabular}

Q18 I feel confident that I will be able to use a condom with a new sexual partner: 


\begin{tabular}{|l|l|l|l|l|l|l|l|} 
& $\begin{array}{l}\text { Strongly } \\
\text { Agree (1) }\end{array}$ & $(2)$ & $(3)$ & $(4)$ & $(5)$ & $(6)$ & $\begin{array}{l}\text { Strongly } \\
\text { Disagree } \\
(7)\end{array}$ \\
\hline $\begin{array}{l}\text { Please } \\
\text { select } \\
\text { one (1) }\end{array}$ & 0 & 0 & 0 & 0 & 0 & 0 & 0 \\
\hline
\end{tabular}

Q19 If I want to use a condom with new sexual partner it will be:

\begin{tabular}{|l|l|l|l|l|l|l|l|} 
& $\begin{array}{l}\text { Extremely } \\
\text { Difficult } \\
(1)\end{array}$ & $(2)$ & $(3)$ & $(4)$ & $(5)$ & $(6)$ & $\begin{array}{l}\text { Extremely } \\
\text { Easy (7) }\end{array}$ \\
\hline $\begin{array}{l}\text { Please } \\
\text { select } \\
\text { one (1) }\end{array}$ & 0 & 0 & 0 & 0 & 0 & 0 & 0 \\
\hline
\end{tabular}

Q20 Please indicate whether you agree or disagree with the statements below.

I intend to use a condom with my next new sexual partner:

\begin{tabular}{|l|l|l|l|l|l|l|l|} 
& $\begin{array}{l}\text { Strongly } \\
\text { Agree (1) }\end{array}$ & $(2)$ & $(3)$ & $(4)$ & $(5)$ & $(6)$ & $\begin{array}{l}\text { Strongly } \\
\text { Disagree } \\
(7)\end{array}$ \\
\hline $\begin{array}{l}\text { Please } \\
\text { select } \\
\text { one (1) }\end{array}$ & 0 & 0 & 0 & 0 & 0 & 0 & 0 \\
\hline
\end{tabular}

Q21 I expect to use condom with my next new sexual partner:

\begin{tabular}{|l|l|l|l|l|l|l|l|}
\hline & $\begin{array}{l}\text { Strongly } \\
\text { Agree (1) }\end{array}$ & $(2)$ & $(3)$ & $(4)$ & $(5)$ & $(6)$ & $\begin{array}{l}\text { Strongly } \\
\text { Disagree } \\
(7)\end{array}$ \\
\hline $\begin{array}{l}\text { Please } \\
\text { select one } \\
(1)\end{array}$ & 0 & 0 & 0 & 0 & 0 & 0 & 0 \\
\hline
\end{tabular}

Q22 I will try to use a condom with my next new sexual partner: 


\begin{tabular}{|l|l|l|l|l|l|l|l|} 
& $\begin{array}{l}\text { Strongly } \\
\text { Agree (1) }\end{array}$ & $(2)$ & $(3)$ & $(4)$ & $(5)$ & $(6)$ & $\begin{array}{l}\text { Strongly } \\
\text { Disagree } \\
(7)\end{array}$ \\
\hline $\begin{array}{l}\text { Please } \\
\text { select } \\
\text { one (1) }\end{array}$ & 0 & 0 & 0 & 0 & 0 & 0 & 0 \\
\hline
\end{tabular}

Q23 I plan to have a condom available for use with my next new sexual partner:

\begin{tabular}{|l|l|l|l|l|l|l|l|}
\hline & $\begin{array}{l}\text { Strongly } \\
\text { Agree (1) }\end{array}$ & $(2)$ & $(3)$ & $(4)$ & $(5)$ & $(6)$ & $\begin{array}{l}\text { Strongly } \\
\text { Disagree } \\
(7)\end{array}$ \\
\hline $\begin{array}{l}\text { Please } \\
\text { select } \\
\text { one (1) }\end{array}$ & 0 & 0 & 0 & 0 & 0 & 0 & 0 \\
\hline
\end{tabular}

Q24 Number of new sexual partners in the past 24 months?

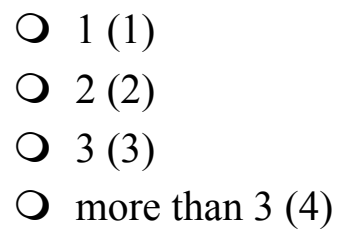

Q25 Did you use a condom when you had sexual intercourse with each new sexual partner?
O Yes (1)
O No (2)
O Sometimes (3)

Q26 The last time I had sex with a new sexual partner, did you use a condom?
O Yes (1)
No (2)

Q27 In the past 24 months, what methods did you use to prevent an STI? (check all that apply) 
a Male Condom (1)

Female Condom (2)

$\square$ Other (please specify) (3)

Q28 In the past 24 months, how often did you use condoms when you had sex with a new partner?

Olways (1)

O Most of the time (2)

O Sometimes (3)

O Never (4)

Q29 If you do not use a condom with a new sexual partner, do you feel your risk of getting and STI is:

O High (1)

O Medium (2)

Low (3)

Q30 Please tell us a little more about why you feel your risk is high, medium or low? (please write your answer in the space provided) 


\section{APPENDIX E}

\section{Pilot Survey Approval}

From: Gay Johnson [mailto:GJohnson@npwh.org]

Sent: Thursday, September 22, 2016 10:29 AM

To: Kimberly Hart

Cc: Lilly Pinto

Subject: NPWH

Hi Kimberly,

You are good to go. It is important, as you know, to keep your work with Bayer separate.

The best way to do this is to distribute the survey away from the exhibit hall and ask the attendees to drop them in a box, that you supply, at the registration desk. Are you still aiming for 50 ?

I have copied Lilly Pinto on this email so that she is aware that you will be providing a box.

Gay

Gay Johnson

Chief Executive Officer

National Association of Nurse Practitioners in Women's Health (NPWH)

505 C Street, NE

Washington, DC 20002

$202-543-9693 \times 3$ phone 202-543-

9858 fax www.npwh.org 


\section{BIBLIOGRAPHY}

Ajzen, I. (1991). The theory of planned behavior. Organizational Behavior and Human Decision Processes, 50(2), 179-211.

Ajzen, I. (2006). Constructing a TPB questionnaire: Conceptual and methodological considerations. Retrieved from http://people.umass.edu/aizen/tpb.html

Akbar, H., Anderson, D., \& Gallegos, D. (2015). Predicting intentions and behaviours in populations with or at-risk of diabetes: A systematic review. Preventive Medicine Reports, 2, 270-282.

doi:10.1016/j.pmedr.2015.04.006

Albarracín, D., Fishbein, M., Johnson, B. T., \& Muellerleile, P. A. (2001).

Theories of reasoned action and planned behavior as models of condom use: A meta-analysis. Psychological Bulletin, 127(1), 142-161.

Anderson, J. E., Warner, L., \& MacAluso, M. (2011). Condom use among US adults at last sexual intercourse, 1996-2008: An update from national survey data. Sexually Transmitted Diseases, 38(10), 919-921.

doi:10.1097/OLQ.0b013e31822545d9

Armitage, C. J., \& Conner, M. (1999). Predictive validity of the theory of planned behaviour: the role of questionnaire format and social desirability. Journal of Community \& Applied Social Psychology, 
9(4), 261-272. doi:10.1002/(SICI)1099-1298(199907/08)9:4<261::AID-

CASP $503>3.0 . C O ; 2-5$

Bader, V., Kelly, P. J., Cheng, A. L., \& Witt, J. (2014). The Role of Previous Contraception Education and Moral Judgment in Contraceptive Use. Journal of Midwifery and Women's Health, 59(4), 447-451.

doi:10.1111/jmwh.12149

Ball, S., Gammon, R., Kelly, P. J., Cheng, A. L., Chertoff, K., Kaume, L., Brotto,M. (2013). Outcomes of stay strong, stay healthy in community settings. Journal of Aging and Health, 25(8), 1388-1397.

doi:10.1177/0898264313507318

Bateson, D. J., Weisberg, E., McCaffery, K. J., \& Luscombe, G. M. (2012). When online becomes offline: Attitudes to safer sex practices in older and younger women using an Australian internet dating service. Sexual Health, 9(2), 152-159.

Beaulaurier, R., Fortuna, K., Lind, D., \& Emlet, C. A. (2014). Attitudes and Stereotypes Regarding Older Women and HIV Risk. Journal of Women and Aging, 26(4), 351-368. doi:10.1080/08952841.2014.933648

Bennett, P., \& Bozionelos, G. (2000). The theory of planned behaviour as predictor of condom use: A narrative review. Psychology, Health and 
Medicine, 5(3), 307-326

M.B. Goldman, R. Troisi, \& K.M. Rexrhode (Eds.), Women and Health (pp. 505-522). Waltham, MA: Academic Press.

Carey, R. F., Lytle, C. D., \& Cyr, W. H. (1999). Implications of laboratory tests of condom integrity. Sexually Transmitted Disease, 26(4), 216-220.

Centers for Disease Control and Prevention. (2011). 10 Ways STDs Impact

Women Differently from Men. Retrieved from www.cdc.gov/std/healthdisparities/stds-women-042011.pdf

Centers for Disease Control and Prevention. (2016). How You Can Prevent Sexually Transmitted Infections. Retrieved from https://www.cdc.gov/std/prevention/default.html

Centers for Disease Control and Prevention. (2017a). Sexually Transmitted Disease Surveillance 2016. Retrieved from https://www.cdc.gov/std/stats16/

Control, Centers for Disease. (2017b). HIV Surveillance Report, 2016 Retrieved from http://www.cdc.gov/hiv/library/reports/hiv-surveillance.html Centers for Disease Control and Prevention. (2017c). HIV in the United States: At A Glance. Retrieved from http://www.cdc.gov/hiv/statistics/overview/ataglance.html Centers for Disease Control and Prevention. (2018). WONDER Online Database. 
Accessed at http://wonder.cdc.gov/std-race-age.html on Mar 16, 2018 $5: 17: 19$

Cheng, A. L., Kelly, P. J., Carlson, K., \& Witt, J. (2014). The Intention of Advanced Practice Registered Nurses to Remain in Positions at Family Planning Clinics Serving Low-Income Women. Journal of Professional Nursing, 30(1), 72-79. doi:10.1016/j.profnurs.2012.12.013

Chesson, H. W., Zaidi, A. A., \& Aral, S. O. (2008). Decreasing age disparities in syphilis and gonorrhea incidence rates in the United States, 1981-2005. Sexually Transmitted Diseases, 35(4), 393-397.

Chimbiri, A. M. (2007). The condom is an 'intruder' in marriage: Evidence from rural Malawi. Social Science and Medicine, 64(5), 1102-1115. doi:10.1016/j.socscimed.2006.10.012

Coleman, C. L., Jemmott, L., Jemmott, J. B., Strumpf, N., \& Ratcliffe, S. (2009). Development of an HIV risk reduction intervention for older seropositive African American men. AIDS Patient Care STDS, 23(8), 647-655. doi:10.1089/apc.2008.0276

Cook, C. (2012). 'Nice girls don't': women and the condom conundrum. Journal of Clinical Nursing, 21(3-4), 535-543. doi:10.1111/j.13652702.2011.03879.x 
Crosby, R., \& Bounse, S. (2012). Condom effectiveness: Where are we now?

Sexual Health, 9(1), 10-17. doi:10.1071/SH11036

Crosby, R., Milhausen, R., Yarber, W. L., Sanders, S. A., \& Graham, C. A.

(2008).Condom 'turn offs' among adults: An exploratory study.

International Journal of STD and AIDS, 19(9), 590-594.

Cumming, G. P., Cochrane, R., Currie, H. D., Moncur, R., \& Lee, A. J. (2012). Web-based survey 'Contraception and attitudes to sexual behaviour' completed by women accessing a UK menopause website. Menopause International, 18(3), 106-109.

D'Anna, L. H., Korosteleva, O., Warner, L., Douglas, J., Paul, S., Metcalf, C., . . .

Malotte, C. K. (2012).

Factors associated with condom use problems during vaginal sex with main and non-main partners. Sexually Transmitted Diseases, 39(9), 687693. doi:10.1097/OLQ.0b013e31825ef325

De Visser, R. O., Badcock, P. B., Rissel, C., Richters, J., Smith, A. M. A., Grulich, A. E., \& Simpson, J. M. (2014). Safer sex and condom use: Findings from the Second Australian Study of Health and Relationships. Sexual Health, 11(5), 495-504. doi:10.1071/SH14102 
Diclemente, R. J., Crittenden, C. P., Rose, E., Sales, J. M., Wingood, G. M., Crosby, R.A., \& Salazar, L. F. (2008). Psychosocial predictors of HIVassociated sexual behaviors and the efficacy of prevention interventions in adolescents at-risk for HIV infection: What works and what doesn't work?

Psychosomatic Medicine, 70(5), 598-605.

doi:10.1097/PSY.0b013e3181775edb

DHHS. (2011). Healthy people 2020. Washington, DC: US Department of Health and Human Services; 2010. Retrieved from.

\section{http://healthypeople.gov/2020/default.aspx}

Drew, O., \& Sherrard, J. (2008). Sexually transmitted infections in the older woman. Menopause International, 14(3), 134-135.

doi:10.1258/mi.2008.008020

Durvasula, R. (2014). HIVIAIDS in Older Women: Unique Challenges, Unmet Needs. Behavioral Medicine, 40(3), 85-98.

doi:10.1080/08964289.2014.893983

Eaton, E. F., \& Hoesley, C. J. (2014). Barrier Methods for Human Immunodeficiency Virus Prevention. Infectious Disease Clinics of North America, 28(4), 585-599. doi:10.1016/j.idc.2014.08.006

Fang, L., Oliver, A., Jayaraman, G. C., \& Wong, T. (2010). Trends in age 
disparities between younger and middle-age adults among reported rates of chlamydia, gonorrhea, and infectious syphilis infections in Canada:

Findings from 1997 to 2007. Sexually Transmitted Diseases, 37(1), 18-25.

Fisher, L. L. P. (2010). Sex, Romance, and Relationships: AARP Survey of Midlife and Older Adults. Retrieved from http://www.aarp.org/research/topics/life/info-2014/srr_09.html

Foster, V., Clark, P. C., Holstad, M. M., \& Burgess, E. (2012). Factors Associated With Risky Sexual Behaviors in Older Adults. Journal of the Association of Nurses in AIDS Care, 23(6), 487-499.

doi:http://dx.doi.org/10.1016/j.jana.2011.12.008

Francis, J., Eccles, M. P., Johnston, M., Walker, A. E., Grimshaw, J. M., Foy, R., Kaner, E. F. S., Smith, L. \& Bonetti, D. . (2004). Constructing questionnaires based on the theory of planned behaviour: A manual for health services researchers. Retrieved from http://openaccess.city.ac.uk/1735

Gallo, M. F., Steiner, M. J., Warner, L., Hylton-Kong, T., Figueroa, J. P., Hobbs, M. M., \& Behets, F. M. (2007). Self-reported condom use is associated with reduced risk of chlamydia, gonorrhea, and trichomoniasis. Sexually Transmitted Diseases, 34(10), 829-833. doi:10.1097/OLQ.0b013e318073bd71

Goesling, B., Colman, S., Trenholm, C., Terzian, M., \& Moore, K. (2014). 
Programs to reduce teen pregnancy, sexually transmitted infections, and associated sexual risk behaviors: A systematic review. Journal of Adolescent Health, 54(5), 499-507. doi:10.1016/j.jadohealth.2013.12.004

Grant, K., \& Ragsdale, K. (2008). Sex and the 'recently single': Perceptions of sexuality and HIV risk among mature women and primary care physicians. Culture, Health and Sexuality, 10(5), 495-511.

Haley, T., Puskar, K., Terhorst, L., Terry, M. A., \& Charron-Prochownik, D. (2013). Condom Use Among Sexually Active Rural High School Adolescents Personal, Environmental, and Behavioral Predictors. Journal of School Nursing, 29(3), 212-224. doi:10.1177/1059840512461282

Harling, G., Subramanian, S. V., Bärnighausen, T., \& Kawachi, I. (2014). Income in equality and sexually transmitted in the United States: Who bears the burden? Social Science and Medicine, 102, 174-182.

doi:10.1016/j.socscimed.2013.11.025 Healthy

People 2020. (2011). Retrieved from http://healthypeople.gov/2020/default.aspx

Herbenick, D., Reece, M., Schick, V., Sanders, S. National Probability Sample of Men and Women Ages 14-94. Journal of Sexual Medicine, 7, 255-265. doi:10.1111/j.1743-6109.2010.02012.x

Herbenick, D., Reece, M., Sck, V., Sanders, S. A., Dodge, B., \& Fortenberry, J. 
D. (2010b). Sexual Behaviors, Relationships, and Perceived Health Status Among Adult Women in the United States: Results from a National Probability Sample. Journal of Sexual Medicine, 7, 277-290.

doi:10.1111/j.1743-6109.2010.02010.x

Idso, C. (2009). Sexually Transmitted Infection Prevention in Newly Single Older Women: A Forgotten Health Promotion Need. Journal for Nurse Practitioners, 5(6), 440-446.

Illa, L., Brickman, A., Saint-Jean, G., Echenique, M., Metsch, L., Eisdorfer, C., . . Sanchez-Martinez, M. (2008). Sexual Risk Behaviors in Late Middle Age and Older HIV Seropositive Adults. AIDS and Behavior, 12(6), 935-942. doi:10.1007/s10461-008-9370-8

Jacobs, R. J., \& Thomlison, B. (2009). Self-silencing and age as risk factors for sexually acquired HIV in midlife and older women. Journal of Aging and Health, 21(1), 102-128.

Kershaw, T. S., Magriples, U., Westdahl, C., Rising, S. S., \& Ickovics, J. (2009).

Pregnancy as a window of opportunity for HIV prevention: Effects of an HIV intervention delivered within prenatal care. American Journal of Public Health, 99(11), 2079-2086. doi:10.2105/AJPH.2008.154476

Kogan, S. M., Brody, G. H., Chen, Y. F., Grange, C. M., Slater, L. M., \& DiClemente, R. J. (2010). Risk and protective factors for unprotected 
intercourse among rural African American young adults. Public Health Reports, 125(5), 709-717.

Kopelowicz, A., Zarate, R., Wallace, C. J., Liberman, R. P., Lopez, S. R., \& Mintz, J. (2015). Using the Theory of Planned Behavior to Improve Treatment Adherence in Mexican Americans With Schizophrenia. Journal of Consulting and Clinical Psychology. doi:10.1037/a0039346 Lachman, M. E. (2001). Handbook of Midlife Development: New York. Wiley \&Sons.

Lazarus, J. V., Sihvonen-Riemenschneider, H., Laukamm-Josten, U., Wong, F., \& Liljestrand, J. (2010). Systematic review of interventions to prevent the spread of sexually transmitted infections, including HIV, among young people in Europe. Croatian medical journal, 51(1), 74-84.

doi:10.3325/cmj.2010.51.74

Liddon, N., Leichliter, J. S., Habel, M. A., \& Aral, S. O. (2010). Divorce and sexual risk among U.S. women: Findings from the national survey of family growth. Journal Women's Health, 19(11), 1963-1967.

Lindau, S. T., Leitsch, S. A., Lundberg, K. L., \& Jerome, J. (2006). Older women's attitudes, behavior, and communication about sex and HIV: A community-based study. Journal of Women's Health, 15(6), 747-753. doi:10.1089/jwh.2006.15.747

Lindberg, L. D., \& Singh, S. (2008). Sexual behavior of single adult American women. Perspectives on Sexual and Reproductive Health, 40(1), 27-33. 
Lovejoy, T. I., \& Heckman, T. G. (2014). Telephone-Administered Motivational Interviewing and Behavioral Skills Training to Reduce Risky Sexual Behavior in HIV-Positive Late Middle-Age and Older Adults. Cognitive and Behavioral Practice, 21(2), 224-236.

doi:http://dx.doi.org/10.1016/j.cbpra.2013.10.003

Lytle, C. D., Routson, L. B., Seaborn, G. B., Dixon, L. G., Bushar, H. F., \& Cyr, W. H. (1997). An in vitro evaluation of condoms as barriers to a small virus. Sexually Transmitted Diseases, 24(3), 161-164.

MacDonald, J., Lorimer, K., Knussen, C., \& Flowers, P. (2015). Interventions to increase condom use among middle-aged and older adults: A systematic review of theoretical bases, behaviour change techniques, modes of delivery and treatment fidelity. Journal of Health Psychology. doi:10.1177/1359105315580462

Mallory, C., Harris, G., \& Stampley, C. (2009). Midlife African-American women's protective and risky evaluation of condoms as barriers to a small virus. Sexually Transmitted Diseases, 24(3), 161-164.

McGoey, T., Root, Z., Bruner, M. W., \& Law, B. (2015). Evaluation of physical activity interventions in youth via the Reach, Efficacy/Effectiveness, Adoption, Implementation, and Maintenance (RE-AIM) framework: A systematic review of randomized and non-randomized trials. Preventive 
Medicine, 76, 58-67. doi:10.1016/j.ypmed.2015.04.006

Midlife. (2015). In Merriam-Webster. Retrieved from http://www.merriamwebster.com/dictionary/midlife

Minkin, M. J. (2010). Sexually transmitted infections and the aging female:

Placing risks in perspective. Maturitas, 67(2), 114-116.

doi:10.1016/j.maturitas.2010.05.003

Montenegro, X. P., Aarp, \& Knowledge, N. (2004). The divorce experience a study of divorce at midlife and beyond conducted for AARP The Magazine. Retrieved from http://www.aarp.org/research/reference/publicopinions/aresearchimport867.html

Moreau, C., Beltzer, N., Bozon, M., \& Bajos, N. (2011). Sexual risk-taking following relationship break-ups. European Journal of Contraception and Reproductive Health Care, 16(2), 95-99.

Mugavero, M. J., Castellano, C., Edelman, D., \& Hicks, C. (2007). Late Diagnosis of HIV Infection: The Role of Age and Sex. The American Journal of Medicine, 120(4), 370-373.

doi:http://dx.doi.org/10.1016/j.amjmed.2006.05.050

Munson, E., Kramme, T., Napierala, M., Munson, K. L., Miller, C., \& Hryciuk, J. E. 
(2012). Female Epidemiology of Transcription-Mediated

AmplificationBased Trichomonas vaginalis Detection in a Metropolitan Setting with a

High Prevalence of Sexually Transmitted Infection. Journal of Clinical

Microbiology, 50(12), 3927-3931. doi:10.1128/JCM.02078-12

National Institutes of Health. (2015). Sexually Transmitted Diseases. U.S.

Department of Health and Human Services Retrieved from http://www.niaid.nih.gov/topics/std/Pages/default.aspx.

Neundorfer, M. M., Harris, P. B., Britton, P. J., \& Lynch, D. A. (2005). HIV-risk factors for midlife and older women. Gerontologist, 45(5), 617-625.

Ott, M. A., Katschke, A., Tu, W., \& Fortenberry, J. D. (2011). Longitudinal associations among relationship factors, partner change, and sexually transmitted infection acquisition in adolescent women. Sexually Transmitted Diseases, 38(3), 153-157. doi:10.1097/OLQ.0b013e3181f2e292

Owusu-Edusei, K., Chesson, H. W., Gift, T. L., Tao, G., Mahajan, R., Ocfemia, M. C. B., \& Kent, C. K. (2013a). The estimated direct medical cost of selected sexually transmitted infections in the United States, 2008.

Sexually Transmitted Diseases, 40(3), 197-201.

doi:10.1097/OLQ.0b013e318285c6d2 
Owusu-Edusei, K., Roby, T. M., Chesson, H. W., \& Gift, T. L. (2013b).

Productivity costs of nonviral sexually transmissible infections among patients who miss work to seek medical care: Evidence from claims data.

Sexual Health, 10(5), 434-437. doi:10.1071/SH13021

Patel, D., Gillespie, B., \& Foxman, B. (2003). Sexual behavior of older women: Results of a random-digit-dialing survey of 2000 women in the United States. Sexually Transmitted Diseases, 30(3), 216-220.

Peterman, T. A., Newman, D. R., Maddox, L., Schmitt, K., \& Shiver, S. (2015).

Risk for HIV following a diagnosis of syphilis, gonorrhoea or chlamydia: 328,456 women in Florida, 2000-2011. International Journal of STD and AIDS, 26(2), 113-119. doi:10.1177/0956462414531243

Peterson, J. A., \& Cheng, A. L. (2013). Physical activity counseling intervention to promote weight loss in overweight rural women. Journal of the American Association of Nurse Practitioners, 25(7), 385-394.

doi:10.1111/j.1745-7599.2012.00794.x

Poynten, I. M., Grulich, A. E., \& Templeton, D. J. (2013). Sexually transmitted infections in older populations. Current Opinion in Infectious Diseases, 26(1), 80-85.

Prati, G., Mazzoni, D., \& Zani, B. (2015). Psychosocial predictors and HIV-related behaviors of old adults versus late middle-aged and younger adults.

Journal of Aging and Health, 27(1), 123-139. 
Ratanasiripong, N. T. (2015). Factors Related to Human Papillomavirus (HPV) Vaccination in College Men. Public Health Nursing, 32(6), 645-653. doi:10.1111/phn.12198

Ratanasiripong, N. T., Cheng, A. L., \& Enriquez, M. (2013). What college women know, think, and do about human papillomavirus (HPV) and HPV vaccine. Vaccine, 31(10), 1370-1376. doi:10.1016/j.vaccine.2013.01.001

Reece, M., Herbenick, D., Schick, V., Sanders, S. A., Dodge, B., \& Fortenberry, J. D. (2010). Condom use rates in a national probability sample of males and females ages 14 to 94 in the United States. Journal of Sexual Medicine, 7(SUPPL. 5), 266-276.

Rich, A., Mullan, B. A., Sainsbury, K., \& Kuczmierczyk, A. R. (2014). The role of gender and sexual experience in predicting adolescent condom use intentions using the theory of planned behaviour. European Journal of Contraception and Reproductive Health Care, 19(4), 295-306.

Rich, E. R. (2001). Negotiation of HIV Preventive Behaviors in Divorced and Separated Women Reentering the Sexual Arena. Journal of the Association of Nurses in AIDS Care, 12(4), 25-35. doi:10.1016/S10553290(06)60214-8

Riebl, S. K., Estabrooks, P. A., Dunsmore, J. C., Savla, J., Frisard, M. I., Dietrich, A. M., ... Davy, B. M. (2015). A systematic literature review and meta 
analysis: The Theory of Planned Behavior's application to understand and predict nutrition-related behaviors in youth. Eating Behaviors, 18, 160-178. doi:10.1016/j.eatbeh.2015.05.016

Ross, P., Humble, Á. M., \& Blum, I. (2013). Sexuality and HIVIAIDS: An Exploration of Older Heterosexual Women's Knowledge Levels. Journal of Women and Aging, 25(2), 165-182.

Sales, J. M., \& Lang, D. L. (2011). Women and sexually transmitted infections:

Scope of the problem and recommendations for prevention. In L. Passero \& C. Sgariglia (Eds.), Sexual Risk Behaviors (pp. 39-62). New York. Nova Sciences.

Sales, J. M., Milhausen, R. R., \& DiClemente, R. J. (2006). A decade in review: Building on the experiences of past adolescent STI/HIV interventions to optimise future prevention efforts. Sexually Transmitted Infections, 82(6), 431-436. doi:10.1136/sti.2005.018002

Sanders, S. A., Reece, M., Herbenick, D., Schick, V., Dodge, B., \& Fortenberry, J. D. (2010). Condom Use During Most Recent Vaginal Intercourse Event Among a Probability Sample of Adults in the United States. The Journal of Sexual Medicine, 7, 362-373. doi:10.1111/j.1743-6109.2010.02011.x 
Sankar, A., Nevedal, A., Neufeld, S., Berry, R., \& Luborsky, M. (2011). What do we know about older adults and HIV? a review of social and behavioral literature. AIDS Care - Psychological and Socio-Medical Aspects of AIDS/HIV, 23(10), 1187-1207. doi:10.1080/09540121.2011.564115

Satterwhite, C. L., Torrone, E., Meites, E., Dunne, E. F., Mahajan, R., Cheryl Fortenberry, J. D. (2010). Sexual behaviors, condom use, and sexual health of americans over 50: Implications for sexual health promotion for older adults. Journal of Sexual Medicine, 7(SUPPL. 5), 315-329.

Sheeran, P., Abraham, C., \& Orbell, S. (1999). Psychosocial Correlates of Heterosexual Condom Use: A Meta-Analysis. Psychological Bulletin, 125(1), $90-132$

Shepherd, J., Kavanagh, J., Picot, J., Cooper, K., Harden, A., Barnett-Page, E., . . . Price, A. (2010). The effectiveness and cost-effectiveness of behavioral interventions for the prevention of sexually transmitted infections in young people aged 13-19: A systematic review and economic evaluation. Health Technology Assessment, 14(7), 1-230. doi:10.3310/hta14070

Sherman, C. A., Harvey, S. M., \& Noell, J. (2005). "Are they still having sex?" STIs and unintended pregnancy among mid-life women. Journal of Women and Aging, 17(3), 41-55.

Skinner, S. R., Parsons, A., Kang, M., Williams, H., \& Fairley, C. (2007). Sexually transmitted infections. Initiatives for prevention. International Journal of Adolescent Medicine and Health, 19(3), 285-294. 
Steiner, M. J., Cates, W., Jr., \& Warner, L. (1999). The real problem with male condoms is nonuse. Sexually Transmitted Diseases, 26(8), 459-462.

Sterk, C. E., Klein, H., \& Elifson, K. W. (2004). Predictors of Condom-Related Attitudes among At-Risk Women. Journal of Women's Health (15409996), 13(6), 676-688.

Stuart, G. S., \& Grimes, D. A. (2009). Social desirability bias in family planning studies: a neglected problem. Contraception, 80(2), 108-112. doi:10.1016/j.contraception.2009.02.009

Swartz, L. H. G., Sherman, C. A., Harvey, S. M., Blanchard, J., Vawter, F., \& Gau, J. (2011). Midlife Women Online: Evaluation of an Internet-Based Program to Prevent Unintended Pregnancy \& STIs. Journal of Women and Aging, 23(4), 342-359.

Upchurch, D. M., Kusunoki, Y., Simon, P., \& Doty, M. M. (2003). Sexual behavior and condom practices among Los Angeles women. Women's Health Issues, 13(1), 8-15. doi:http://dx.doi.org/10.1016/S1049-3867(02)00175-5 Warner, L., Stone, K. M., Macaluso, M., Buehler, J. W., \& Austin, H. D. (2006). Condom use and risk of gonorrhea and chlamydia: A systematic review of design and measurement factors assessed in epidemiologic studies.

Sexually Transmitted Diseases, 33(1), 36-51.

doi:10.1097/01.olq.0000187908.42622.fd Weller, S., \& Davis, K. (2002). Condom effectiveness in reducing heterosexual HIV transmission. 
Cochrane database of systematic reviews (3), Cd003255.

doi:10.1002/14651858.cd003255

World Health Organization. Sexually Transmitted Infections. Retrieved from http://www.who.int/topics/sexually_transmitted_infections/en/

Xu, F., Schillinger, J. A., Aubin, M. R., St. Louis, M. E., \& Markowitz, L. E. (2001).

Sexually transmitted diseases of older persons in Washington State.

Sexually Transmitted Diseases, 28(5), 287-291.

Zablotsky, D., \& Kennedy, M. (2003). Risk factors and HIV transmission to midlife and older women: Knowledge, options, and the initiation of safer sexual practices. Journal of Acquired Immune Deficiency Syndromes, 33(SUPPL.

2), S122-S130.

Zemore, S. E., \& Ajzen, I. (2014). Predicting substance abuse treatment completion using a new scale based on the theory of planned behavior. Journal of Substance Abuse Treatment, 46(2), 174-182.

doi:10.1016/j.jsat.2013.06.011 
Kimberly Colette Hart was born November 9, 1968, in Watervliet, Michigan. She graduated in 1991 from Union College in Lincoln, Nebraska with a Bachelor of Science degree in Nursing. After working for several years in labor and delivery, pediatrics and obstetrical/pediatric home care she returned to school and in 1996 earned a Master's degree in Nursing as a women's health nurse practitioner from Vanderbilt University. Kimberly has a wide range of women's health experience in the healthcare field from inpatient nursing, home care nursing, office based practice as a women's health nurse practitioner and in the pharmaceutical industry in both marketing and currently in medical affairs. She began her doctoral degree in July, 2010 at the University of Missouri - Columbia, while working full time throughout, completed her PhD in April 2018. Kimberly has been a passionate advocate for women's health throughout her professional career. Following completion of her terminal degree, Kimberly plans to continue to facilitate women's health education and advance the role of nursing, in public health and other health sciences while working to promote patient focused positive health outcomes for all women. Her research interest area(s) include health behavior change and health education, social determinants of health and community-based participatory research. 